\title{
Las organizaciones de inmigrantes chinos en Argentina
}

\author{
Chinese immigrant organizations in Argentina
}

\author{
ALEJANDRO GRIMSON* \\ GUSTAVO NG** \\ LUCIANA DENARDI***
}

\begin{abstract}
RESUMEN: Este estudio está enfocado en las organizaciones de inmigrantes chinos en Argentina; la migración desde Taiwán se intensificó en los años setenta y ochenta, mientras que la proveniente de China continental se acrecentó en las décadas posteriores. En la actualidad prevalece una fuerte tendencia de inserción económica y laboral de los inmigrantes en un nicho específico: los supermercados. Esta actividad ha planteado una dispersión territorial de los migrantes que tienden a residir cerca de su zona de trabajo. La inmigración china en Argentina presenta varias peculiaridades. Es una inmigración más nueva que en Estados Unidos, en la cual hay un peso relativo muy relevante de Taiwán, mucho más pequeña en términos demográficos, más dispersa en la ciudad, muy distante de su país de origen en términos geográficos y en un contexto económico con menor capacidad de ahorro en dólares. Todos estos factores plantean una cierta limitación del desarrollo del transnacionalismo. Sin embargo, hay indicios claros de un transnacionalismo incipiente.
\end{abstract}

PALABRAS ClaVE: inmigración, organizaciones, transnacionalismo, China, Argentina.

ABSTRACT: This study focuses on Chinese immigrant organizations in Argentina. Migration from Taiwan intensified in the 1970s and 1980s, while the flow that originated in continental China occurred in the preceding decades. There is currently a strong trend toward economic and labor integration of immigrants within a specific niche: supermarkets. This activity has led to a geographic dispersal of migrants who tend to reside near their area of employment. Chinese immigration to Argentina exhibits a number of peculiarities. It is a more recent kind of immigration that that which occurred in the United States, in which Taiwan was more heavily represented; it is much smaller in demographic terms, more dispersed across the cities, very far from the country of origin in geographic terms and in an economic context, with a lower savings capacity in dollars. All of these factors result in a certain limitation in the development of transnationalism. However, there are clear indicators of a nascent transnationalism.

KEY WORDS: migration, organizations, transnationalism, China, Argentina.

* Doctor en Antropología (Universidad de Brasilia); Profesor Titular de la Universidad Nacional de San Martín e investigador del Conicet.

**Técnico en Ciencias de la Comunicación por la Escuela de Periodistas del Círculo de la Prensa.

***Licenciada en Sociología (UnVm, Córdoba, Argentina); Mgtr. en Antropología Social (IDAES/ UNSAM-IDES). 


\section{INTRODUCCIÓN}

E ste trabajo busca sintetizar algunas conclusiones de un estudio acerca de las organizaciones chinas en Argentina. La migración desde Taiwán se intensificó en los años setenta y ochenta, mientras que la proveniente de China continental —en su mayoría de provincias costeras - se acrecentó en las décadas posteriores. En la actualidad prevalece una fuerte tendencia de inserción económica y laboral de los inmigrantes en un nicho específico: los supermercados. En Buenos Aires es conocido el "barrio chino», unas cuatro cuadras donde hay comercios y restaurantes chinos y taiwaneses. Pero en contraste con otras ciudades donde una porción significativa de la inmigración china se concentra en un espacio geográfico, la actividad de supermercados que no sólo se realiza en Buenos Aires, sino en La Plata, Mar del Plata, Rosario, Córdoba y otras ciudades, ha planteado una dispersión territorial de los migrantes que tienden a residir cerca de su zona de trabajo. Como se trata del desarrollo de un comercio de cercanía, como opción a los antiguos almacenes de barrio pero también a las grandes cadenas de hipermercados, para que resulte conveniente instalar un nuevo comercio de este tipo es importante que no haya otro previamente en el barrio.

Cuando se consideran realidades como las de Estados Unidos, la inmigración china en Argentina presenta varias peculiaridades. Es una inmigración más nueva, en la cual hay un peso relativo muy relevante de Taiwán, mucho más pequeña en términos demográficos, más dispersa en la ciudad, muy distante de su país de origen en términos geográficos y en un contexto económico con menor capacidad de ahorro en dólares. Todos estos factores plantean una cierta limitación del desarrollo del transnacionalismo. Sin embargo, nuestros datos indican la existencia de un transnacionalismo incipiente.

Para realizar el presente estudio, se desarrolló una estrategia metodológica que incluyó: 1) veinte entrevistas estructuradas de un cuestionario para líderes de organizaciones; 2) observaciones en rituales, cenas y actos; 3) elaboración de un listado propio de más de 80 organizaciones. Es relevante señalar

$26 \frac{\text { PRIMER SEMESTRE } 2016}{\text { MIGRACIÓN Y DESARROLLO NÚM. } 26}$ 
que en comparación con otros estudios sobre grupos migratorios en Argentina, ciertamente la técnica de la bola de nieve ofrece resultados parciales y muy lentos entre los chinos continentales. Los motivos pueden ser diversos, desde una migración nueva (dos décadas), desconfianza o temor. El hecho es que esa dificultad tornó imposible acceder a entrevistas fuera de la ciudad de Buenos Aires, a excepción de la ciudad de La Plata.

Esta dificultad puede explicarse a través de varias aristas. En el trabajo de campo etnográfico con taiwaneses, al indagar sobre las actividades económicas de los informantes, éstos nos advirtieron que «los chinos no hablan de negocios», en parte ante la incertidumbre de su concreción. Otra informante nos advirtió que «los taiwaneses no hablan de negocios por miedo a que otro les copie». La tendencia que manifiestan los informantes es que si a un "paisano» le va bien vendiendo determinado producto, rápidamente los demás comienzan a vender lo mismo.

Por otro lado, la cuestión de la «sangre» parecería ser un factor que determina la confianza que puede depositarse en el otro. Sólo uno de los autores, haciendo alusión a su ascendencia china, logró conseguir acceso a las asociaciones de residentes y conocer a determinadas personas influyentes en la comunidad. La poca visibilidad de las asociaciones de residentes, camufladas tras restaurantes chinos, no brinda otra posibilidad que llegar a ellas a través de conocidos y brindando las credenciales necesarias.

Finalmente, los inmigrantes chinos en otras ciudades son escasos y sólo en Rosario, La Plata y Mar del Plata están nucleados en asociaciones formalizadas. Otros miembros del equipo intentaron entrevistar asociaciones en estas y otras ciudades y no tuvieron éxito, encontrándose con respuestas como «no funciona más, no conozco». Entre los taiwaneses la disposición fue diferente. Para entrevistar algunas organizaciones utilizamos el contacto de un representante de la comunidad de ultramar que logró que las mismas personas que teníamos interés en entrevistar nos llamaran para ponerse a disposición. 


\section{BREVE RESEÑa de LA HISTORIA dE LA MIGRACIÓN CHINA ${ }^{1}$}

Si bien existen registros de la presencia de algunos cientos de inmigrantes provenientes de China en el Censo Nacional de 1914, se trataba de hombres solos que no alcanzaban el medio millar. Aunque la inmigración se incrementó luego de 1949, en los años setenta comenzó una «ola migratoria» de chinos que en su mayoría escapaba al régimen comunista (Trejos y Chaing, 2012; Sassone y Mera, 2006; Bretal, 2006). En los años ochenta se observa la llegada de numerosas familias taiwanesas, como reacción al miedo a la guerra o expansión de China sobre la isla de Taiwán. Otras de las razones por las que los taiwaneses deciden migrar tienen que ver con la alta densidad poblacional de la isla, que motivó la salida de familias enteras buscando lugares más seguros, menos contaminados, que mejoraran su calidad de vida. Estos migrantes contaban con dinero suficiente para montar sus negocios o comprar viviendas una vez instalados en Argentina (Bogado, 2002). A mediados de los noventa, la cantidad de taiwaneses ascendía a 25,000 personas, de las cuales 23,000 vivían en Buenos Aires y alrededores (Pappier, 2011).

Bogado (2002) y Pacceca y Courtis (2008) afirman que desde 1990 a 1999 se dio un importante flujo de migrantes chinos hacia Argentina. Mayoritariamente llegaban sin capital aunque con grandes expectativas de progreso económico. Eligieron Argentina por considerarlo un país «seguro» y por la situación de crecimiento económico de la que gozó el país hasta 1997.² En la década de los noventa, fuentes extraoficiales afirmaban que existían entre 40,000 y 45,000 chinos en Argentina, de los cuales la mitad eran taiwaneses (Bogado, 2002).

Los migrantes taiwaneses que llegaron a Argentina en la década de los setenta y ochenta remiten grandes diferencias con la migración china de los años noventa y los años 2000. Los taiwaneses deciden migrar por diversas

${ }^{1}$ Este apartado se construyó en base al artículo de Denardi, titulado «Ser chino en Buenos Aires: historia, moralidades y cambios en la diáspora china en Argentina» y aprobado para su publicación en la revista Horizontes Antropológicos de junio de 2015.

${ }^{2}$ En esa década, el gobierno argentino había instaurado la Ley de Convertibilidad, por la cual un peso argentino era equivalente a un dólar estadounidense.

$28 \frac{\text { PRIMER SEMESTRE } 2016}{\text { MIGRACIÓN Y DESARROLLO NÚM. } 26}$ 
razones, entre ellas una mejor calidad de vida, ${ }^{3}$ la ruptura con la tradición, ${ }^{4}$ o por razones políticas: ya sea el temor a que se desate una guerra con China o por persecución ideológica. ${ }^{5}$ La decisión de migrar es acompañada por un «consejo» que proviene de allegados a los que respetan. Pueden ser familiares o proveedores de sus negocios, pero varios recalcan la idea de una persona prestigiosa, cuya opinión es tenida en cuenta. Generalmente migran las familias enteras, quienes al llegar son ayudados por parientes o amigos que ya se encuentran instalados en el país.

La mayoría de los migrantes taiwaneses argumenta haber tenido un buen pasar económico de la mano de sus profesiones que una vez que llegan a Argentina deciden abandonar, fundamentalmente por las dificultades para homologar los títulos universitarios. A las cuestiones burocráticas se suman las dificultades con el lenguaje — ninguna familia sabía hablar español al llegar y muchos migrantes aún hoy siguen sin aprenderlo, pues sus hijos hacen de traductores cuando lo necesitan-, y por las propias de las relaciones bilaterales entre Argentina y Taiwán. ${ }^{6}$

Las actividades en las que se desempeñan al llegar al país son básicamente el comercio - almacenes pequeños o grandes, atendidos por toda la familia y restaurantes de cocina china-. Los hijos de estos migrantes asistieron a la universidad y ya son profesionales que se desempeñan en diversas áreas, como la informática, la contabilidad, la docencia, las ciencias médicas y el comercio.

${ }^{3}$ Fundamentalmente, lo que no permite esta calidad de vida en Taiwán es la superpoblación - la isla tiene la superficie de la provincia de Tucumán, un 80 por ciento de suelo habitable, y 22 millones de habitantes, castigados por la contaminación y los tifones.

${ }^{4}$ Algunos informantes mencionaron su disconformidad ante el rol que la tradición familiar china les asigna. Uno de ellos decidió migrar, en parte, porque no quería trabajar para mantener a sus hermanos, como se espera del hijo mayor. Otro decide buscar nuevos horizontes para así evitar casarse con la persona elegida por sus padres.

${ }^{5}$ Diversos miembros de las iglesias presbiteranas manifestaron que la decisión de migrar surgió de saber que sus nombres figuraban en listas negras.

${ }^{6}$ Cuando Argentina entabló relaciones diplomáticas formales con la República Popular China, el 19 de febrero de 1972, Taiwán cerró su embajada en Argentina. Un año después se estableció la Oficina Comercial de Taiwán en Argentina. En 1996 esta Oficina cambió su nombre por el de Oficina Comercial y Cultural de Taipei. El 9 de julio de 1992 el gobierno argentino estableció la Oficina Comercial y Cultural de Argentina en Taipei. 
Al llegar a Argentina, en su mayoría las familias residen en barrio de clase media, o media alta, envían a sus hijos a escuelas privadas sin importar si pertenecen a la religión católica, ya que entienden que será más exigente que una de gestión pública, y los fines de semana asisten al «Colegio Chino» para aprender mandarín, instrumentos musicales chinos, artes marciales, etcétera. Como afirma Denardi (2015), en las familias taiwanesas la educación de los hijos también incluye algún instrumento musical o un deporte y el aprendizaje de inglés. Reivindicando la procedencia de una sociedad con menos de 1 por ciento de analfabetismo, los taiwaneses valoran positivamente que los hijos tengan un título universitario, lo cual a veces entra en tensión con la «raíz comerciante de la cultura china».

Respecto al idioma, los taiwaneses mayores de 60 años escasamente hablan español, manejándose principalmente con chino y «taiwanés». ${ }^{7}$ Los migrantes o hijos de migrantes de entre 30 y 40 años hablan fluidamente español, mandarín y en algunos casos dialecto taiwanés, muy utilizado en la cotidianidad del hogar. Actualmente, en estas generaciones se observa una revalorización económica de un rasgo anteriormente discriminador. Con el auge de los intercambios entre China y Argentina, los jóvenes bilingües están siendo muy solicitados como traductores e intérpretes. Los jóvenes y niños en su mayoría reniegan del idioma de sus padres: éstos afirman que entienden cuando se les habla en chino pero que responden en español.

Por su parte, la migración de la República Popular China es más reciente y presenta ciertas especificidades. Los inmigrantes llegan en promedio alrededor de los 25 años, desde zonas empobrecidas de China (Fujian, principalmente), sin capital económico y con menor instrucción - muchos de los migrantes no hablan mandarín sino dialecto-. Al llegar, compran un fondo de comercio de un supermercado, deuda que se suma a la que supuestamente contrajeron para viajar a Argentina. Según el relato de algunos informantes,

${ }^{7}$ Es el dialecto de Min nan, el Min nan Hua. En Buenos Aires, los taiwaneses se refieren a este dialecto como «taiwanés». Los hijos de taiwaneses, además del chino mandarín aprenden el dialecto porque es de uso cotidiano en el hogar. La Iglesia presbiterana taiwanesa más tradicional conserva el «culto» en taiwanés. La asociación civil de taiwaneses también realiza actividades informales en ese dialecto.

$30 \frac{\text { PRIMER SEMESTRE } 2016}{\text { MIGRACIÓN Y DESARROLLO NÚM. } 26}$ 
para abaratar costos o para evitar robos, ${ }^{8}$ viven en habitaciones contiguas o pisos superiores del negocio. La actividad económica predominante, con la dispersión geográfica y las extensas jornadas laborales que implica, genera escasa formación y participación en las asociaciones culturales chinas.

En Buenos Aires encontramos un supermercado propiedad de migrantes chinos cada dos o tres cuadras. ${ }^{9}$ Esta saturación de la ciudad los llevó a expandirse a las segundas ciudades del país, como Rosario, Córdoba y Mar del Plata. Desde la Federación de Supermercadistas Chinos, se estima que en Argentina existen actualmente 8,900 supermercados, de los cuales 3,500 se encuentran en el Gran Buenos Aires y la Ciudad Autónoma. Por dar un ejemplo, el gobierno de la ciudad de La Plata decidió que no puede haber un supermercado chino a menos de 600 metros uno de otro, de modo que se produjo una distribución muy regular en la ciudad. ${ }^{10}$ Dada esta saturación, los migrantes chinos y taiwaneses comenzaron a abrir «rostizerías» de venta de comida preparada al peso. Una forma de diferenciar las rostizerías de dueños taiwaneses es que son vegetarianas. La comida que venden los propietarios chinos no es únicamente china, sino que encontramos carnes y pastas, por lo que se transformaron en una opción variada, sana y económica para almorzar durante la jornada laboral, sobre todo en zonas de oficinas.

Paralelamente al supermercadismo, inmigrantes chinos desarrollaron otra actividad comercial, ésta sí basada en la importación: venta mayorista de juguetes y artículos de bajo precio y consumo masivo. Al contrario de los

${ }^{8}$ Diversas noticias periodísticas, quizás con algo de información, quizás a veces reproduciendo estereotipos, hablan de la presencia de "mafias chinas», que regularían cuestiones del comercio y su seguridad. También aluden a trata de personas.

${ }^{9}$ La cuestión de los supermercados es tan central en la comunidad que llega a las iglesias. Durante el culto del domingo por la mañana en una iglesia presbiterana a la que asisten muchos migrantes de la República Popular China (RPC), se leyeron lecturas en torno a escuchar las respuestas de Dios, para saber cómo actuar, ya que «Él sabe que es lo mejor para cada uno». En la prédica, uno de los ancianos ilustró el tema con situaciones cotidianas de los fieles. En primer lugar, dijo que un hombre de negocios al que le proponían un negocio, se tomaba tres días para escuchar a Dios y sólo después de escucharlo daba una respuesta a la contraparte. También mencionó a un dueño de supermercado que escuchó que Dios le indicaba que se prepare para la visita de un inspector. Al día siguiente, cuando llegó el inspector a su local, pudo afrontarlo sin problemas porque se había preparado, gracias a Dios.

${ }^{10}$ La Asociación de Comerciantes Chinos de La Plata (ACCLP) respalda esta decisión. 
supermercados, que por su tipo de actividad debían estar dispersos en el territorio, estos locales están concentrados en el muy comercial barrio de Once. ${ }^{11}$

Últimamente están llegando al país jóvenes chinos motivados por aprender el español, que se desempeñan como profesores de idioma chino para argentinos y realizan estudios de posgrado en las universidades locales. Empleados y ejecutivos llegan tanto a empresas chinas que radican en Argentina (Sinopec, Axion Energy), como a empresas locales compradas por China (ICBC, Sierra Grande, Nidera). Mantienen una calidad de vida muy superior a la de sus compatriotas: residen en barrios cerrados o en zonas exclusivas de la ciudad de Buenos Aires, viajan tres veces por año a China haciendo escala en Europa por algunos días, visten ropa costosa y a la moda y salen a cenar a los restaurantes chinos más exclusivos. ${ }^{12}$ Aunque cuantitativamente este grupo es ínfimo, ${ }^{13}$ contrasta con la representación que tiene la inmigración china en algunos grupos de la sociedad argentina.

Los supermercados y restaurantes propiedad de migrantes chinos desde su instalación han sufrido diversos embates discriminatorios y delictivos. Mediáticamente, se reproduce el prejuicio de que apagan las heladeras de los lácteos durante la noche para ahorrar energía, que cocinan ratas, que son sucios, que almacenan alimentos frescos junto a la basura, etcétera. ${ }^{14}$ Recién a finales de 2013, desde la comunidad taiwanesa, dos voceros tuvieron

${ }_{11}$ Para analizar las relaciones entre chinos, coreanos y judíos en los barrios de Once y Flores véase Castiglione, s/d y Bialogorski y Bargman, 1996).

12 Se trata de restaurantes de alta categoría que se diferencian del resto de los restaurantes chinos que tienen menús económicos y una orientación más «familiar». Ambos tipos tienen salones privados más o menos improvisados, pero sólo hemos constatado que se realicen karaokes en los restaurantes más populares.

${ }^{13}$ Una nota de reciente publicación, estima el número de empresarios y profesionales chinos en 3,000 personas: http://www.cronista.com/3dias/La-invasion-silenciosa-los-goldenboys-chinos-desembarcan-en-la-Argentina-20140725-0007.html Lamentablemente, el título de la nota ya nos indica una impugnación moral a la presencia de estos ciudadanos chinos en nuestro país.

${ }^{14}$ Existe una asociación de vecinos del Barrio de Belgrano que se dedica a denunciar, sacar fotos y publicar en internet estas situaciones, de la que los medios se hacen eco. En este blog se denuncia, además, un encubrimiento del gobierno de la ciudad (http://belgranodenuncia.blogspot.com.ar/). 
derecho a réplica en los medios locales. Desde la Asociación Barrio Chino se está trabajando para "educar al comerciante». Reconocen que en algunos locales de venta de comida a la calle en el Barrio Chino se cocina en el piso, como los migrantes están acostumbrados a hacer en sus lugares de origen. Su tarea entonces implica enseñar a estos comerciantes que las leyes argentinas no permiten esa manera de cocinar. ${ }^{15}$

En síntesis, mientras que la inmigración china se ha producido más recientemente y en mayor número, los taiwaneses llegaron hace más de 40 años y alcanzan 20 por ciento de la población china. Esto se traduce en una diferencia significativa en términos de aprendizaje de idioma e integración a la sociedad de residencia. La actividad laboral que desarrollan los migrantes no ha variado a lo largo de estos años. Los taiwaneses que llegaron en los setenta y ochenta instalaron «almacenes» o «supermercados», restaurantes, lavaderos de ropa y casas de revelado de fotos, rubros en los que no hace falta conocer demasiado el idioma del lugar de residencia. Los migrantes chinos que llegaron desde 2004 desarrollaron los supermercados como principal medio de inserción económica, lo cual tuvo dos consecuencias que hacen a la particularidad de la comunidad china en Argentina: por un lado, generó una dispersión urbana de la «comunidad», es decir, que la mayoría de ellos no vive en el Barrio Chino y su participación en asociaciones es relativamente menor que la de los taiwaneses, debido a las largas jornadas laborales.

\section{El PROBLemA DE LA CANTIDAD DE INMIGRANTES CHINOS}

Los datos estadísticos correspondientes a la población china y taiwanesa en Argentina tienen tres grandes problemas. En primer lugar, muchos migrantes

${ }^{15}$ Algunas notas que hemos publicado al respecto: Luciana Denardi, «Deconstruyendo prejuicios». Portal on line, revista Dang Dai. http://dangdai.com.ar/joomla/index.php? option $=$ com_content $\& v i e w=$ article $\&$ id $=3009$ : deconstruyendo-prejuicios \&catid $=3$ :contribuciones\&Itemid $=11$

Gustavo Ng y Luciana Denardi, «El cultivo del entendimiento», revista Dang Dai, núm. 9, otoño de 2014. http://dangdai.com.ar/joomla/index.php?option=com_flippingbook\&vie $\mathrm{w}=$ book\&id $=4 \&$ page $=1 \&$ Itemid $=28$ 
más allá de la situación legal no responden a los censistas, por lo que las cifras oficiales difieren marcadamente de las no oficiales. En segundo lugar, en los datos, gráficos y tablas no siempre se distingue entre China y Taiwán, a consecuencia de la política argentina de no reconocer a Taiwán como país independiente. Finalmente, existen escasos registros de los primeros flujos de migración, su composición y densidad (Casals, 2009).

Los datos del Censo de Población, Hogares y Viviendas de 2010, arrojan una cantidad de casi 9 mil personas que nacieron en la República Popular China y casi 3 mil que nacieron en Taiwán. ${ }^{16}$ Sin embargo, la Dirección Nacional de Migraciones ofrece una información diferente. Entre los años 2004 y 2013 se presentaron 26,237 trámites de radicación de inmigrantes chinos ante esa entidad. La mitad, 13,088, fueron resueltas positivamente como radicación temporaria, lo cual supera al registro censal. Pero además, 17,505 fueron resueltas como radicación permanente. Es decir, al resolverse radicaciones solicitadas con anterioridad, hubo más otorgadas que solicitadas.

Por otra parte, en función de distintas fuentes y cálculos, diferentes autores realizan sus propias estimaciones de la cantidad de chinos en la Argentina: para 2001 entre 30 y 50 mil (Zuzek, 2004), 120,000 para 2007 (Zhang Tuo, 2007), 80,000 para 2008 (Guerra Zamponi, 2010) y diversos líderes comunitarios afirman que actualmente habría 200,000 chinos o más.

\section{Organizaciones chinas en Argentina: PRIMERA APROXIMACIÓN}

En los diferentes procesos migratorios, las dinámicas organizacionales son diversas. Hasta ahora, hemos relevado la existencia de 81 organizaciones chinas y taiwanesas en Argentina. Las asociaciones de residentes (27 por ciento), religiosas (20 por ciento) y económicas (16 por ciento) son las más numerosas. También encontramos organizaciones culturales abocadas a la difusión de la cultura china para la sociedad argentina como también para

${ }^{16}$ http://200.51.91.245/argbin/RpWebEngine.exe/PortalAction?\&MODE $=$ MAIN\&BASE $=$ CPV2010B\&MAIN=WebServerMain.inl

$34 \frac{\text { PRIMER SEMESTRE } 2016}{\text { MIGRACIÓN Y DESARROLLO NÚM. } 26}$ 
afianzar los lazos de la comunidad china en el país con su cultura de origen (4 por ciento); educativas, fundamentalmente colegios chinos para miembros de la comunidad y para argentinos (3 por ciento); civiles, dedicadas al trabajo con la comunidad (12 por ciento); deportivas ( 6 por ciento) y periodísticas (5 por ciento).

Podemos considerar este relevamiento como una aproximación adecuada al tipo de organizaciones existentes, pero sus proporciones entre paréntesis deben ser consideradas con cautela. Las organizaciones de residentes implican algún modo de institucionalización de redes extendidas de vecindad, parentesco y lingüísticas. Tienen diferencias evidentes con las organizaciones económicas: su trabajo es interno a la comunidad, se basa en relaciones de confianza y no está dirigido a establecer vínculos formales con la sociedad argentina. Todo esto redunda en que pueden mantener, a diferencia de las iglesias, de los colegios o de las organizaciones de supermercadistas, niveles de exposición pública muy bajos. Por lo tanto, mientras creemos haber sido exhaustivos en relevamientos religiosos y económicos, pensamos que hay más organizaciones de residentes de las que hemos podido registrar hasta ahora.

En general, se trata de organizaciones que combinan en mayor o menor medida, actividades económicas, culturales y sociales: algunas cámaras comerciales desarrollan actividades culturales, así como algunas iglesias también realizan actividades educativas. Si bien 48 por ciento de las organizaciones relevadas pertenecen al grupo chino, la mayoría de éstas no cuentan con tanta visibilidad (participación en eventos y la apertura de las instituciones hacia los argentinos) regularidad y antigüedad como las taiwanesas (véanse gráficas 1 y 2 del Anexo).

Incluimos las categorías chino-taiwanesas, chino-argentinas y argentino-taiwanesas, ya que algunas organizaciones son «binacionales». La mayoría de las organizaciones así catalogadas son corporaciones económicas, entre ellas la Federación de Supermercados y Asociaciones Chinas en la República Argentina (Fesach), que si bien su director ejecutivo es argentino, reúnen a una parte de los supermercadistas chinos y la Cámara Comercial e Industrial Argentino-Taiwanesa que agrupa en su mayoría empresas 
argentinas para el intercambio con Taiwán. Por otro lado, más allá de los colegios chinos que son presididos por taiwaneses y aceptan niños chinos en sus clases, encontramos tres organizaciones donde conviven chinos y taiwaneses. Es el caso de Muralla Dorada, que si bien tiene fuerte vinculación con la Embajada China y sus líderes son chinos, la mayoría de sus colaboradores son taiwaneses. También encontramos la Asociación Cultural Chino-Argentina, en la que si bien las fundadoras son taiwanesas, su objetivo es ser un referente de la cultura china en Argentina, y dentro de su staff de docentes encontramos tanto chinos como taiwaneses y argentinos, lo que es significado por los miembros de esta organización como una fortaleza, como un signo de «integración» o "fusión» exitosa. ${ }^{17}$ Del mismo modo, la asociación que nuclea los comercios del Barrio Chino tiene como objetivo mejorar la infraestructura del mismo para atraer más turismo. Si bien está presidida por taiwaneses, muchos de los comercios adheridos son propiedad de inmigrantes chinos.

\section{Organizaciones entreVISTADAS}

\section{Grupo, tipo y antigüedad}

De las 20 organizaciones entrevistadas en el Área Metropolitana de Buenos Aires y La Plata, 10 son chinas, 4 taiwanesas, 3 chino-taiwanesas, 2 chinoargentinas y 1 taiwanesa-argentina. Las organizaciones más antiguas del grupo de las taiwanesas datan de los años 1971, 1978 y 1983. Del grupo chino las más antiguas datan de 1968, 1984 y 1985. Las iglesias y asociaciones cívicas son las que más tempranamente se fundaron en el grupo taiwanés, mientras que en el grupo chino, la más antigua es una iglesia cristiana, la de 1984 es un periódico y la de 1985 una cámara de empresas chino- argentinas.

${ }_{17}$ El éxito consiste en demostrar que personas argentinas pueden desarrollar con excelencia artes chinas - como tai chi o sumi-e-, y a la inversa, que personas chinas o taiwanesas pueden desarrollar con excelencia artes locales, como el baile del tango.

$36 \frac{\text { PRIMER SEMESTRE } 2016}{\text { MIGRACIÓN Y DESARROLLO NÚM. } 26}$ 
Las asociaciones más importantes y tradicionales de Taiwán se ubican en el Barrio Chino, pero también encontramos escuelas e iglesias en barrios como Almagro, Villa Crespo, Villa del Parque y Palermo. Las organizaciones chinas están ubicadas en toda la ciudad. Las económicas se ubican en el centro de Buenos Aires, en las cercanías de los edificios públicos y del mercado cambiario porteño. Varias asociaciones entrevistadas no cuentan con una sede propia, sino que utilizan casas familiares, restaurantes o sedes de otras asociaciones para reunirse. Estas reuniones se pautan con escasa anticipación y no son regulares, sino de acuerdo con las necesidades que van surgiendo en la actividad de los miembros.

De las 20 asociaciones, casi la mitad fue adscripta a más de un tipo. Por lo general observamos que las organizaciones económicas tienen una fuerte impronta cultural y educativa (véase gráfica 3 del Anexo).

A continuación señalaremos los datos más relevantes que surgen de estas 20 entrevistas.

Para qué se crearon las organizaciones

Más de 30 por ciento de las organizaciones encuestadas afirmaron haberse creado para el desarrollo de actividades comerciales. Le siguen en porcentaje las creadas para celebrar fiestas y tradiciones (21 por ciento). Sin embargo, es interesante notar que de las seis organizaciones que afirmaron ser creadas para celebrar fiestas, sólo tres lo hacen de manera exclusiva. Las otras tres también tienen entre sus fundamentos el desarrollo de actividades culturales y la organización de eventos. En palabras de un encuestado, la necesidad de reunirse y realizar las actividades tradicionales en determinadas fechas surge por la lejanía con el lugar de origen y por el deseo de mostrar a sus hijos las raíces de la familia. Si bien esto puede haber fomentado la creación de las asociaciones más antiguas, muchos líderes de las organizaciones manifestaron la intención de lograr una mayor apertura hacia la sociedad argentina. Una manera de lograr esa apertura es realizando eventos culturales que 
atraen a los argentinos. ${ }^{18}$ También observamos que, como afirma Laborde (2011), hay una tendencia a trabajar en la integración a la sociedad argentina en tanto los migrantes se construyen como "productores culturales». ${ }^{19}$

Otros motivos de creación de las asociaciones mencionadas son la enseñanza del idioma chino, la idea de ser un «puente» entre chinos y argentinos para favorecer el intercambio, el conocimiento mutuo, la representación política de las organizaciones ya creadas, el apoyo mutuo entre los miembros de la asociación frente a adversidades y la difusión cultural (véase gráfica 4 del Anexo).

\section{Los objetivos}

Las organizaciones económicas se proponen promover el acercamiento, la vinculación y el apoyo entre los miembros de la asociación persiguiendo dos objetivos diferentes. Por un lado, las asociaciones de supermercadistas pueden ser un vehículo para negociar con otra capacidad con proveedores y con el Estado. Por otro, aquellas vinculadas a la importación y exportación buscan tender los puentes y la gestión necesaria para dinamizar el comercio.

Las organizaciones de tipo cultural y educativo trabajan el acercamiento entre la comunidad china y la sociedad de recepción. Sus objetivos, entonces, rondan en la enseñanza del idioma y la difusión cultural para disminuir los prejuicios entre chinos y argentinos, posicionarse como un "puente» para disminuir los «choques culturales» entre los diferentes grupos de ambas culturas. Las organizaciones religiosas se abocan enteramente a la

${ }^{18}$ El festejo del año nuevo chino en las Barrancas de Belgrano contó con 120,000 personas que se acercaron durante un fin de semana a disfrutar de muestras de artes marciales, bailes, música, caligrafía, etc., según estimaciones de los organizadores. Los migrantes chinos no disfrutan de este evento, sino que trabajan en los stands de venta de comida y artículos chinos típicos.

${ }^{19}$ El Instituto «Confucio» de la UBA no tiene relación con la colectividad china, mientras el Instituto «Confucio» de la Universidad Nacional de La Plata suele coorganizar algunas actividades.

$38 \frac{\text { PRIMER SEMESTRE } 2016}{\text { MIGRACIÓN Y DESARROLLO NÚM. } 26}$ 
«evangelización» y la "cultivación», ${ }^{20}$ pero también pueden buscar insertarse en redes religiosas de colectividades migrantes procurando puentes y formas específicas de integración.

El 65 por ciento de las organizaciones señalan que sus objetivos están centrados exclusivamente en la Argentina y otro 20 por ciento «principalmente en Argentina». La Federación de Supermercadistas, una organización muy relevante, está incluida en esa gran mayoría. Las tres organizaciones entrevistadas que desarrollan sus objetivos en ambos países son la Cámara Comercial e Industrial Argentino-Taiwanesa, la Cámara de la Producción, la Industria y el Comercio Argentino-China y la Unión General de Residentes Chinos y Ciudadanos de Origen Chino en Argentina. Esto significa que las organizaciones económicas de menor envergadura, y las organizaciones culturales, civiles y religiosas, no tienen el alcance como para desarrollar sus objetivos en los países de procedencia de sus miembros (véanse gráficas 5 y 6 del Anexo).

También preguntamos cuál era el segundo objetivo más importante. Encontramos tres grandes grupos de respuestas:

- La unidad entre los miembros de la organización;

- La defensa de los comerciantes y la lucha contra la discriminación y disminuir los prejuicios para con los chinos;

- El apoyo a los comerciantes de la asociación, mediante gestiones ante la Embajada, recepción de funcionarios y gestión de relaciones comerciales en el interior de la red y con grupos de interés de la sociedad de recepción.

Las asociaciones de residentes chinos (por dar un ejemplo, Asociación de Residentes de Jiangxi) presentan la particularidad de invertir el orden respecto al resto de las organizaciones: como primer objetivo señalan la unificación de la comunidad china para apoyarse mutuamente, mientras que el

20 Una de las organizaciones religiosas, que dice enfrentar situaciones de persecución tanto en China como en Argentina, prefiere no ser catalogada como una asociación de este tipo, sino de «cultivación». 
segundo objetivo implica la promoción de actividades comerciales entre chinos, y entre argentinos y chinos.

\section{Actividades}

Cada una de las organizaciones realiza diversos tipos de actividades. 15 de las 20 organizaciones encuestadas realiza algún tipo de actividad cívicocultural, generalmente la celebración de fiestas patrias o chinas como el Año Nuevo, Baño del Buda o Vesak, el Doble Diez, la Fiesta de las Linternas o Faroles, la Fiesta de la Luna, entre otros.

La otra actividad desarrollada por gran cantidad de organizaciones (12 de 20) son las actividades solidarias. Esto consiste fundamentalmente en el envío de dinero a víctimas de las catástrofes que castigan sus países de procedencia (el terremoto en China de 2009 y los tifones de Taiwán en diferentes años); la donación de alimentos a catástrofes de los lugares de residencia (la inundación de la ciudad de La Plata en 2013); la colaboración con sectores empobrecidos de Buenos Aires, Misiones, Chaco, a través de la donación de alimentos o la construcción de templos, entre otros.

La actividad educativa es desarrollada por nueve organizaciones, al igual que la ayuda a familias o individuos en dificultades. Las actividades educativas incluyen cursos de chino, conferencias empresariales, charlas con dueños de supermercados y restaurantes sobre manipulación de alimentos y regulación argentina en cuanto a higiene y salubridad, convenios con universidades chinas y taiwanesas para el otorgamiento de becas estudiantiles, hasta las escuelas dominicales de las iglesias. Respecto a la ayuda a familias o individuos, se menciona la colaboración ante la pérdida de documentos, robo de dinero o bienes.

Diversas organizaciones realizan actividades políticas como la recepción de funcionarios y empresarios chinos en Buenos Aires. Sin embargo, es frecuente que no deseen explayarse sobre estos temas, quizás porque no pretenden establecer con claridad las relaciones en cada caso entre las organizaciones y Estado. También hay estudios de abogados, algunos de los cuales

$$
40 \frac{\text { PRIMER SEMESTRE } 2016}{\text { MIGRACIÓN Y DESARROLLO NÚM. } 26}
$$


están formados por migrantes o hijos de migrantes, que se dedican especialmente a la tramitación de documentos. Las organizaciones prefieren mencionar el asesoramiento en diversas cuestiones legales a sus miembros.

Otras actividades que fueron nombradas son las relacionadas con los medios de comunicación — periódicos semanales, programas de televisióny el turismo en Argentina y Sudamérica para los socios de la organización (véase gráfica 7 del Anexo).

\section{Características de las organizaciones}

Al menos 16 de las organizaciones encuestadas están registradas legalmente en Argentina, lo cual indica un importante proceso de formalización. Cinco inclusive cuentan con exención de impuestos. Las organizaciones taiwanesas están también registradas en la Oficina Comercial y Cultural de Taiwán en Argentina.

Los procesos de toma de decisiones son muy variables entre las organizaciones, pero en más de la mitad las juntas directivas o comités tienen un peso relevante. En otras, en cambio, las decisiones las toma el líder, a veces asesorado por personas externas a la organización, otras veces por personas de gran trayectoria y prestigio en el interior de la misma, como los «ancianos». Sólo en el 15 por ciento de las asociaciones el líder ha permanecido en su lugar por más de 10 años, siendo dos de ellas organizaciones pequeñas, encabezadas por sus fundadoras. Una particularidad se da entre las iglesias presbiteranas que encuestamos. Mientras en una hace más de 10 años que la misma persona lidera la institución, en la otra nos describieron un pormenorizado sistema de elecciones de los líderes que toman las decisiones. No se trata sólo del pastor, sino de un grupo de «ancianos». Los adultos mayores de la organización eligen a un líder que está en el cargo tres años, y que no puede tener dos cargos consecutivos. La elevada edad de las personas que toman las decisiones parece ser común en organizaciones taiwanesas. En una asociación de residentes nos comentaban la extrañeza que les genera 
que los miembros de la organización y más aún los líderes, no sobrepasen los 50 años (véase gráfica 8 del Anexo).

El 61 por ciento de las organizaciones tiene menos de 50 miembros. Entre éstas figuran las pequeñas cámaras de empresarios, las organizaciones dedicadas a la enseñanza del idioma y la difusión cultural, el periodico chino y algunas asociaciones de residentes. Le siguen las organizaciones de más de 200 miembros, con un porcentaje del 17 por ciento. Entre ellas encontramos iglesias, y cámaras de supermercados (véase gráfica 9 del Anexo).

Si bien muchas organizaciones funcionan económicamente gracias a contribuciones de los miembros, algunas reciben apoyos del gobierno de Taiwán o de la República Popular China para actividades culturales y educativas.

\section{LOS MIEMBROS DE LAS ORGANIZACIONES}

Entre las organizaciones entrevistadas, tendiendo a generalizar, podría decirse que los miembros de las organizaciones taiwanesas nacieron en Argentina o llegaron muy jóvenes, tienen alto nivel educativo (universitario), son ciudadanos argentinos o tienen los papeles migratorios completamente en orden, y la mayoría tiene entre 40 y 55 años.

Los miembros de organizaciones chinas, en general migraron hace más de diez años, son residentes legales pero no ciudadanos, ya que en Argentina nunca hubo motivaciones muy especiales para nacionalizarse (el número de nacionalizaciones fue bajo incluso en la inmigración europea) y en el caso de los chinos ellos perderían la nacionalidad china.

Entre los taiwaneses existe una ruptura generacional que se traduce en las organizaciones. Hace pocos años se creó una asociación comercial de jóvenes de menos de 40 años, que depende de una cámara mayor, pero que se diferencia en forma y actividades. Su objetivo es agrupar a jóvenes descendientes de taiwaneses que quieren abrirse su propio camino comercial y que ya no desean trabajar con sus padres, por las diferencias que surgen

$42 \frac{\text { PRIMER SEMESTRE } 2016}{\text { MIGRACIÓN Y DESARROLLO NÚM. } 26}$ 
entre ellos en relación con las estrategias comerciales y la escasa valoración que los mayores le darían a la voz de los más jóvenes.

Las asociaciones de residentes chinos muestran elevados porcentajes de miembros de entre 25 y 40 años, lo que coincide con los datos migratorios que mencionamos anteriormente: la migración china a Argentina es de jóvenes en edad económicamente activa. En estas asociaciones los mayores de 55 años no llegan al 5 por ciento o al 10 por ciento de sus miembros, lo que genera cierta desorientación en organizaciones que hacen de sus «ancianos» consultores muy preciados.

En las asociaciones de residentes y comerciantes chinos que entrevistamos, el 100 por ciento de los miembros trabaja en su negocio o empresa. Sólo en el caso del periódico encontramos un alto porcentaje de profesionales en una organización china. En las organizaciones taiwanesas la proporción de profesionales o técnicos es más elevada. Aquí se evidencia la brecha existente en las dos comunidades. Mientras la mayoría de las organizaciones chinas tienen entre sus miembros a comerciantes, las organizaciones taiwanesas tienen en sus miembros a profesionales y en menor medida comerciantes.

Las cámaras comerciales evidencian una composición heterogénea en cuanto a las actividades laborales de sus miembros. En ellas encontramos en diferentes proporciones a dueños de empresas o negocios, profesionales y técnicos y trabajadores manuales. La participación en organizaciones tiende a favorecer las posibilidades de conexiones y de trabajo. La posibilidad o no de ser leal a China siendo ciudadano argentino no recae en la participación en la organización, sino que pareciera una decisión personal de cada migrante. La mayoría de los encuestados afirma que no ponen las obligaciones hacia su país por encima de la integración. Dos tercios piensa que es posible integrarse a la sociedad argentina y seguir participando en la vida social y política del país de origen.

En los supermercados y en las casas es muy común que se vea el canal estatal CCTV. También miran telenovelas taiwanesas, escuchan pop asiático, comen comidas tradicionales, mandan a los niños a estudiar chino los fines de semana, muchos de ellos asisten relacionados con la colectividad y leen 
diarios y revistas comunitarias en chino, organizan números artísticos y deportivos asociados a las tradiciones chinas.

El 75 por ciento de las organizaciones aproximadamente afirma contribuir a la integración de sus miembros en la sociedad de recepción; en algunos casos porque la composición de la organización es heterogénea en cuanto al origen de los miembros, en otros casos por brindar información a los miembros de las leyes argentinas que permitan un mejor desempeño de su actividad, por abrir los eventos al público argentino, entre otras razones. En el caso de Fessach, la integración viene de la mano de la colaboración que brindan los supermercadistas a la comunidad de recepción. Desde las asociaciones de comercio, la integración es de tipo jurídica y comercial; en algunas asociaciones de residentes la integración con esa red puede ser un paso relevante para la obtención de créditos que permitan la inserción económica.

Algunas organizaciones manifestaron no contribuir a la integración de sus miembros a la sociedad argentina, ya que sus objetivos y sus miembros no lo requieren. La Iglesia China afirmó que los participantes de los «Cultos» no tienen planeado quedarse en el país. La mayoría de ellos son supermercadistas que luego de un tiempo en Argentina, seguirán su viaje hacia Estados Unidos. Prueba de ello es que la institución surge en los años sesenta, y según nos informaron, la mayoría de los miembros hace menos de 10 años que está en el país. La asociación civil taiwanesa negó su contribución a la integración de sus miembros a la sociedad argentina debido a que, según nuestro entrevistado, no ingresan migrantes taiwaneses a Argentina en la actualidad y la asociación sólo está abierta a las personas con pasaporte taiwanés y sus familias. Otras asociaciones de residentes chinos y asociaciones comerciales chinas manifestaron que no es el cometido de la organización. Finalmente, otra organización manifestó que tener un alto porcentaje de argentinos entre sus miembros implica que la organización no trabaje en esta cuestión.

La integración de los chinos a la sociedad argentina viene referenciada por la inserción económica y fundamentalmente por mostrar, a través de los eventos y celebraciones, "lo mejor de la cultura china», para que sus miembros sean mejor recibidos. 


\section{Actividades CON OTRAS ENTIDADES CHINAS}

De las organizaciones encuestadas, 15 afirmaron realizar actividades con otras entidades chinas y taiwanesas en Argentina. La actividad que nuclea a muchas de las organizaciones que encuestamos es la organización del Año Nuevo Chino. ${ }^{21}$ Existe un círculo de organizaciones que siempre participa de los eventos del gobierno de Caba que los integra cultural y espacialmente con la ciudad (Laborde, 2011). Éstas son la Asociación Barrio Chino, ACCA, Fundación Muralla Dorada, Fesach, que tienen sus vinculaciones con el templo budista Fong Guan Shan y determinadas escuelas de artes marciales. Por otro lado, las mismas organizaciones taiwanesas tienden a reunirse en todas las celebraciones del año: asociación civil de taiwaneses, Fundación Tzu Chi (budista), y otras escuelas de artes marciales.

Las organizaciones que no realizan actividades con otras organizaciones chinas son dos: Una iglesia presbiterana y la organización religiosa Falun Dafa, quienes afirman que las organizaciones chinas tienen temor a vincularse con ellos.

\section{Relaciones institucionales y políticas en Argentina}

Un 60 por ciento de las organizaciones tiene relación con representantes del poder ejecutivo argentino, alrededor del 40 por ciento tiene vinculaciones con representantes del poder legislativo argentino. Son relaciones eventuales por actividades culturales, por oportunidades comerciales, problemas aduaneros, por actividad de los supermercados, por temas de inmigración y discriminación, entre otros. Generalmente, las mismas asociaciones tienen vínculos estables con determinadas oficinas y funcionarios. Las asociaciones de residentes no tienen vínculos con las autoridades ejecutivas o legislativas argentinas.

${ }^{21}$ No se trata de la misma celebración. En Buenos Aires se realizan al menos tres celebraciones - en las Barrancas de Belgrano, en la Asociación Civil de Taiwaneses, en la Embajada de China-; en la ciudad de La Plata se realiza otro evento. 
Las asociaciones culturales tienen vínculos y contactos con autoridades argentinas para desarrollar sus actividades y eventos. Las asociaciones que participan en la organización del Año Nuevo Chino están más vinculadas a jefes comunales y a las direcciones de cultura de la ciudad de Buenos Aires. Mientras que las organizaciones económicas tienden a entablar relaciones con aduanas, secretarías de Comercio, Jefatura de Gabinete, entre otros.

Casi la mitad de las organizaciones encuestadas afirman haber organizado proyectos o acuerdos con entidades de Argentina. En buena medida se trata de acuerdos eventuales que no generan necesariamente planes de acción sostenidos en el tiempo. En algunos casos las entidades con las que se tienen proyectos en común pertenecen a otros colectivos migrantes o religiosos — asociaciones judías, de las comunidades japonesa y coreana-. Otras organizaciones mantienen actividades conjuntas con los gobiernos provinciales o municipales. Finalmente, las organizaciones más pequeñas, con escasos contactos con representantes de los poderes ejecutivo y legislativo argentinos, tienden a vincularse entre sí. Por ejemplo, las iglesias presbiteranas realizan eventos deportivos entre los miembros de las tres iglesias taiwanesas de Buenos Aires. Lo mismo sucede con otras asociaciones taiwanesas, como los colegios.

En contextos de discriminación a través de los medios de comunicación donde a veces se estigmatiza a los chinos identificándolos con la «mafia china», o allí donde los inspectores municipales clausuran por cualquier motivo comercios chinos, las organizaciones activan sus redes locales. A veces apelando a la embajada y otras veces de forma directa, buscan revertir decisiones que consideran injustas. En el contexto inflacionario argentino, el gobierno nacional estableció negociaciones con los grandes supermercados y también con los supermercados chinos, para instrumentar el plan "precios cuidados» u otras medidas similares. Así, la dirigencia de la Federación de Supermercados tiene un vínculo aceitado con los funcionarios correspondientes del Ministerio de Economía de la Nación.

$46 \frac{\text { PRIMER SEMESTRE } 2016}{\text { MIGRACIÓN Y DESARROLLO NÚM. } 26}$ 


\section{EL TRANSNACIONALISMO INCIPIENTE}

Las relaciones que las organizaciones mantienen con China y Taiwán presentan intensidades muy diversas. Si bien existen casos de ausencia de relación de la organización con el país de origen, casi 60 por ciento de las organizaciones tiene relación con representantes del poder ejecutivo chino, y alrededor del 30 por ciento tiene vinculaciones con representantes del poder legislativo chino.

Antes de continuar, es necesario resaltar cuatro restricciones objetivas que establecen diferencias entre los inmigrantes chinos en Argentina de los que viven en Estados Unidos: la distancia física, el costo del pasaje, el bajo peso demográfico y el carácter bastante nuevo de la migración.

A pesar de ello, en nuestra investigación observamos que diversas organizaciones en Argentina tienen vínculos con mediadores institucionales (la Embajada China, la Oficina Comercial y Cultural de Taiwán) o mediadores más informales, como algunas personalidades que sirven también de nexo o representación. El presidente de la Unión de Residentes Chinos en Argentina, a quien recurren los líderes de las asociaciones de residentes locales, manifestó tener vinculación con autoridades de 12 ciudades chinas diferentes: Fujian, Heilongjian, Yunnan, Jiling, Sicuani, Xiamen, Sichuan, Beijing, Fuzhuo, Nanjin, Hebei, Ningde.

Las asociaciones de residentes son el tipo de organización más vinculado a cuestiones de vecindad y parentesco, a redes de ayuda mutua y las que menos vínculos formales establecen. Las asociaciones de comerciantes locales y supermercadistas no realizan ninguna actividad de importación y en tanto tales no tienen vinculaciones formales con China, sino con Argentina. Las cámaras y federaciones más importantes —en cuanto a antigüedad y cantidad de empresas que nuclean- son los que mantienen más vínculos con representantes de ambos poderes en ambos países (véanse gráficas 10 y 11 del Anexo).

Los proyectos que las organizaciones encuestadas realizan con organizaciones en China/Taiwán están en su mayoría (7 de 14) vinculadas con el comercio o con las organizaciones de las cuales se desprenden. Es decir, las 
Cámaras de Comercio de Taiwán en Argentina, la Juvenil y la Mayor, desarrollan proyectos en Taiwán de la mano de la Cámara Comercial de Taiwán. Lo mismo sucede con las iglesias presbiteranas. Las actividades que diferentes organizaciones realizan en China están destinadas a atraer inversiones hacia Argentina y no a la inversa.

Es habitual que la palabra «política» genere temor o rechazo, incluso para quien teje vínculos con los gobiernos u organizaciones políticas. Dieciséis organizaciones afirmaron no involucrarse con ninguna actividad política. Sólo dos manifestaron involucrarse en política, pero diferenciándose de la política partidaria. Una de ellas es la Cámara de la Producción, la Industria y el Comercio Argentino-China. La otra es la organización Falun Dafa que denuncia mediáticamente en Argentina acciones del gobierno chino de persecución de sus miembros en China.

Hay datos recogidos en otros contextos del estudio que permiten visualizar un gran interés por la construcción de lazos políticos. En el transcurso de la investigación se produjo la visita del presidente de la República Popular China a Argentina. Las asociaciones de más diverso tipo atravesaron una situación de efervescencia. En las semanas previas a la llegada del presidente $\mathrm{Xi}$ Jinping, una parte significativa de las asociaciones fue recibiendo y agasajando a algunos funcionarios que formaron parte de los preparativos de la visita.

Pudo vislumbrarse su interés en no quedar excluidos de ninguna actividad relevante que pudiera haber, así como de acceder a las esferas más altas que resultara posible. Las redes más formales e informales se activaron en las semanas previas. Durante la breve visita, varias organizaciones y sus miembros mantuvieron una situación de "alerta» en el sentido de que podrían ser convocados para cualquier actividad o una fotografía. De hecho, fueron convocadas para actividades de acompañamiento y celebración de la visita, con vínculos más estrechos de que previamente habíamos podido detectar. Los representantes de las diferentes asociaciones nucleadas en la Unión General de Residentes Chinos y Ciudadanos de Origen Chino en Argentina manifestaron su bienvenida al presidente Xi en el momento de su llegada al hotel Sheraton, donde se hospedó, y en su visita al Congreso de la

$48 \frac{\text { PRIMER SEMESTRE } 2016}{\text { MIGRACIÓN Y DESARROLLO NÚM. } 26}$ 
Nación. En ambos casos se manifestaron en la calle (y protagonizaron momentos de tensión con Falún Dafa). El presidente de la Unión General de Residentes Chinos y Ciudadanos de Origen Chino en Argentina, tuvo un encuentro con el presidente $\mathrm{Xi}$ - el resto de los líderes no-. Todas las asociaciones de la Unión recibieron a diferentes líderes que llegaron a Buenos Aires anticipando la visita presidencial.

\section{PARTICIPACIÓN Y VínCULOS CON EL PAís DE ORIGEN DE LOS MIEMBROS DE LA ORGANIZACIÓN}

Casi el 80 por ciento de las organizaciones encuestadas indicaron estar de acuerdo respecto a que la participación ayuda a mantener vínculos con el país de origen. Una de las que prefirió no opinar al respecto tiene relaciones casi cotidianas con China continental. Si bien la mayoría de las organizaciones manifestaron estar de acuerdo con que la organización ayuda a la comunidad a mantener relaciones con el país de origen, aumenta la cantidad de respuestas neutrales. Esta respuesta puede deberse a una mera descripción de la realidad (las organizaciones tienen más vínculos que sus miembros) o a una creciente reserva, una prevención ante preguntas que les resultan algo inquietantes (véanse gráficas 12 y 13 del Anexo).

\section{Actividades desarrolladas en China}

Una parte significativa de las organizaciones, especialmente las organizaciones culturales y religiosas, no tienen actividades en China ni en Taiwán. Sus objetivos y su actividad están centrados en Argentina; eso no significa que no existan redes y lazos con China, lo cual es particularmente evidente en algunas organizaciones religiosas que reciben visitas y mantienen una comunicación sobre sus tareas.

Evidentemente, el mayor contraste es con las cámaras comerciales y empresariales, donde el objetivo mismo implica necesariamente una vinculación 
constante. Las asociaciones de residentes chinos tienen muchas actividades en relación con China, en su mayoría de tipo comercial: tanto con delegaciones comerciales argentinas como con la promoción de inversiones chinas en Argentina. Las otras organizaciones que tienen actividades en China son las federaciones de empresas chino-argentinas dedicadas a la importación y exportación entre ambos países. Cabe aclarar que una de estas federaciones es promovida básicamente por argentinos sin participación relevante de inmigrantes. ${ }^{22}$

Inclusive, la Confraternidad Min-nan en Argentina considera que uno de sus principales objetivos es servir de puente entre las empresas creadas por las personas de esa zona que residen en Argentina y Min-nan. Buscan que empresas de la zona vengan a realizar negocios al país y poder importar mercaderías desde esa zona a Argentina. Ya hay organizaciones, no sólo específicamente económicas, que buscan exportar a china productos argentinos. La exportación se da en el marco de una actividad importadora previa. Exportan para poder importar, en el esquema de comercio exterior estipulado por el gobierno nacional.

En las vinculaciones políticas, la mayoría de las organizaciones de inmigrantes chinos tienen una relación habitual con la embajada y con visitantes políticos que llegan desde China. Por ejemplo, la Unión General de Residentes Chinos y Ciudadanos de origen chino en Argentina puede hacer una cena en homenaje a un visitante político ilustre que visita el país. Evidentemente, una enorme parte de los vínculos económicos y políticos entre los inmigrantes chinos y China tienen el apoyo de la embajada. Cuando entrevistamos a un importante dirigente de una asociación comercial y de una asociación de residentes, le señalamos un portarretrato donde se había colocado una foto del embajador. Él hizo dos cosas. Primero dijo «siempre», con orgullo, y después mostró una foto con otro embajador anterior. Estos

22 En la reciente visita del presidente Xi Jinping y más de 200 empresarios chinos a Argentina, esta Cámara Chino-Argsentina logró que empresarios chinos y argentinos firmaran casi 30 convenios, cartas de intención de compra, contratos y acuerdos de compra. Los principales productos comprados por empresas chinas son lana, glicerina, soja, carne vacuna y mariscos congelados, vino y leche.

$50 \frac{\text { PRIMER SEMESTRE } 2016}{\text { MIGRACIÓN Y DESARROLLO NÚM. } 26}$ 
vínculos hacen que, a veces, los dirigentes de organizaciones puedan convertirse en colaboradores de visitantes importantes de China, facilitando su recepción y acompañándolos en viajes por el país.

\section{COMUNICACIÓN, VIAJES Y CONTACTOS con China y desde China}

La comunicación de las organizaciones con China o Taiwán no es muy frecuente. La que mantiene comunicación con más frecuencia es la organización económica más importante en Argentina, la Cámara de la Producción, la Industria y el Comercio Argentino-China que lo hace diariamente. La empresa que edita un periódico en chino en Buenos Aires y que a la vez sus periodistas son corresponsales para la prensa china, mantiene un contacto fluido. Las asociaciones de residentes chinos presentan la misma particularidad que notáramos respecto a los contactos con autoridades de China: la Unión de Asociaciones se comunica con China unas dos veces por semana, pero varias de las asociaciones que nuclea no mantienen ninguna comunicación (véase gráfica 14 del Anexo).

La comunicación que las organizaciones en Argentina reciben desde China o Taiwán es sensiblemente menor. En las asociaciones de residentes chinos se repite lo que veíamos anteriormente, mientras que algunas organizaciones taiwanesas indican que la comunicación se realiza vía Oficina Comercial y Cultural (véase gráfica 15 del Anexo).

Dadas las distancias y costos de los viajes entre Argentina y Taiwán o China, los miembros de las organizaciones no los emprenden con frecuencia. Una organización que realiza viajes frecuentes es la Cámara ArgentinoTaiwanesa fundamentalmente, con motivo de la participación en ferias empresariales. El resto de las organizaciones que con más frecuencia viaja son las asociaciones de residentes y comerciantes chinos (véase gráfica 16 del Anexo). 


\section{Problemas de las organizaciones}

Los problemas relevados en las organizaciones encuestadas pueden ser agrupados en las siguientes categorías:

- Falta de apoyo tanto de los gobiernos - argentino, taiwanés, chino-como de las empresas de la comunidad a la que pertenece la organización.

- Falta de recursos económicos y de maneras para obtenerlos, sobre todo en las asociaciones que no cobran cuotas a sus miembros, como la Asociación Civil Chinos de Taiwán y las iglesias.

- Falta de participación de los miembros y generar interés en los hijos de migrantes.

- "Choque cultural», «diferencia de valores» y conflictos intergeneracionales.

- «Inseguridad» (robos, saqueos a supermercados chinos).

- Dentro de las organizaciones taiwanesas, el hecho de que Argentina no reconozca su estatus de gobierno independiente genera problemas al momento de negociar, importar y exportar que deben ser permanentemente salteados por sus miembros.

- En otro orden de problemáticas, Falun Dafa refiere al hecho de la persecución de sus miembros y el espionaje de sus líderes.

\section{Proyectos}

En las entrevistas pudimos relevar los siguientes proyectos:

- Enseñanza del idioma chino en colegios privados y públicos. No sólo es un proyecto de la organización abocada a esta tarea, sino también de organizaciones económicas y de residentes, apoyadas por la Embajada de China desde hace muchos años. Relacionado con esto, muchas organizaciones se plantean promover la enseñanza del idioma y la cultura china a los hijos de migrantes.

- Organización de eventos, cursos de capacitación en higiene, manipulación de alimentos, protocolo, seminarios y ferias. 
- A nivel de infraestructura, muchas organizaciones se plantean conseguir o construir un lugar propio, sobre todo las asociaciones de residentes. Otra organización se plantea mejorar el Barrio Chino — peatonalizar las calles, el tratamiento de la basura, y la iluminación.

- Inauguración de nuevas filiales en otras ciudades, presentes en las agendas de iglesias y asociaciones de residentes.

- Apertura de las organizaciones a los argentinos - fundamentalmente las más cerradas a los miembros de la comunidad de origen - para dar a conocer el lugar de origen, las costumbres y la cultura y así colaborar con una convivencia armoniosa, desterrando prejuicios.

- Búsqueda de apoyos estatales.

- Reforzar la integración de los chinos en Argentina, a través de la enseñanza del español a los chinos.

\section{RELACIONES Y TENSIONES:}

\section{CONFLICTOS ENTRE CHINOS CONTINENTALES Y TAIWANESES}

Dadas las particularidades de la migración china y taiwanesa en Argentina, descritas en los apartados anteriores, en la investigación que desarrollamos observamos que la categoría identitaria «chino» no se utiliza sólo para dar cuenta del origen nacional de las personas, sino también para indicar una pertenencia cultural, y en el caso de los taiwaneses, una diferenciación moral (Denardi, 2013).

De acuerdo con esto, podríamos distinguir «ser chino en sentido estrecho» (sólo los inmigrantes que provienen de zonas donde se reconoce la jurisdicción de la República Popular China) de "ser chino en sentido amplio»:23 todos aquellos que por sus costumbres y sus antepasados se sienten parte de la cultura china, a pesar de haber nacido en Taiwán. Como hemos mostrado, hay organizaciones sólo para chinos continentales, otras sólo para taiwaneses, y otras en las que chinos y taiwaneses conviven sin diferencias.

${ }^{23}$ Utilizando las mismas palabras de la definición Edel y Edel sobre la ética: "Ethics wide» y «ethics narrow» (Edel y Edel, 1959). 
Para los chinos que provienen de la China continental, no hay razones para dar cuenta de esa distinción: para ellos Taiwán es parte de China, por lo que no hay necesidad de discriminar entre unos y otros. En cambio entre los taiwaneses encontramos chinos en sentido amplio que mantienen una férrea postura de diferenciación moral respecto a los chinos continentales.

Además, para comprender el punto de vista de los chinos continentales es necesario entender el peso que tienen las regiones. De hecho, todas las asociaciones de residentes están organizadas en función de las diferentes provincias. Incluso, algunas zonas dentro de las provincias tienen relevancia en términos identitarios y organizacionales, como Fuqien, Fuzhou, Zhenjiang y Min-nan. Es común que ellos se refieran a los inmigrantes provenientes de otras regiones como si se tratara de personas de otro país. En ese sentido, no tienen una visión a priori de los taiwaneses como más distantes simbólicamente que los provenientes de otras regiones. Hay que considerar que la región de la que han venido más inmigrantes continentales es Fujian, dividida de la isla de Taiwán por el estrecho del mismo nombre, y que comparte lazos con la gente de Min-nan, que identifica a la vez a una zona de Fujian y a un grupo lingüístico con muchas similitudes con los habitantes de la isla. Además, el hecho de que sea una migración con pocos años se expresa en aspectos dinámicos: la Asociación de Ultramar de Chinos de Wenzhou decidió modificar su nombre por Zhenjiang, ya que así pueden incluir a quienes llegan desde toda la provincia y no sólo desde su capital.

Dentro de los migrantes taiwaneses mayores, quienes en la década de los setenta y ochenta llegaron con alrededor de 40 años al país, hay una tendencia a diferenciarse de los chinos continentales. Muchos de los adultos mayores que se reúnen en la Asociación de Chinos de Taiwán del Barrio Chino, muy vinculada a la Oficina Comercial de Taiwán en Argentina, son partidarios de la defensa de la cultura china que en Taiwán conservó su «pureza». Por ejemplo, estos taiwaneses se muestran reacios a leer los caracteres del chino simplificado, se oponen a la enseñanza del pinyin, manteniendo en los colegios taiwaneses la enseñanza del idioma a través del bopomofo. ${ }^{24}$

${ }^{24}$ El pinyin es un sistema de enseñanza del idioma chino, la representación de la fonética se realiza en letras romanas. El bopomofo es aún hoy el sistema oficial que se imparte en Taiwán

$54 \frac{\text { PRIMER SEMESTRE } 2016}{\text { MIGRACIÓN Y DESARROLLO NÚM. } 26}$ 
Llegados a Buenos Aires, se instalaron en el Barrio de Belgrano y abrieron comercios en la calle Arribeños, conocida entre los migrantes como "Calle Taiwán», ya que al principio «éramos todos taiwaneses». Eligieron esa zona por su ubicación segura, por los vecinos de buen nivel adquisitivo y por la diversidad de medios de transporte que la convierten en un lugar accesible (Pappier, 2011). En la década de los ochenta sólo contaba con un restaurante («Todos contentos»), un supermercado ("Casa China») y la Asociación Civil Chinos de Taiwán. Pasados pocos años fueron instalándose el Colegio Sin Heng y el templo budista Tchong Kuan de Motañeses. Llegada la crisis de 2001, muchos comerciantes taiwaneses se vieron obligados a cerrar sus negocios y es entonces cuando la migración proveniente de China continental reabre comercios. En el año 2003 una líder comunitaria renueva una mansión en la calle Arribeños donde abre una casa de té y galería de arte e impulsa la Asociación Vecinal Arribeños que encara proyectos para incluir al Barrio en el circuito turístico de Belgrano (Pappier, 2011).

Si 2003 fue una bisagra en la que el Barrio Chino comenzó a pensarse como un destino turístico desde el Gobierno de la Ciudad y desde la comunidad, los Juegos Olímpicos de Beijing en 2008 y la instalación del Arco en 2009 fueron una segunda bisagra. Además de las disputas dadas entre los vecinos no chinos y los chinos (véase Lacarrieu, 2013 y Laborde, 2011), la instalación del Arco en 2009 generó conflictos en el interior de la «comunidad». ${ }^{25}$ Según nuestros informantes, los taiwaneses lo vieron como una invasión al

para la enseñanza del idioma, mediante símbolos fonéticos. La enseñanza del idioma chino está dividida en Argentina. Los argentinos recurren en su mayoría al Centro de Idiomas Universitarios, dependiente de la Universidad de Buenos Aires o a asociaciones privadas para aprender chino simplificado a través del pinyin. En cuestiones de idioma, el Instituto «Confucio» de La Plata tiene más incidencia que el de Buenos Aires. Los taiwaneses tienen más de cinco colegios en la ciudad de Buenos Aires, donde el porcentaje de argentinos es mucho menor, pero reciben cerca de 300 chicos chinos y taiwaneses, de 3 a 17 años los fines de semana. En esos colegios se enseña con el sistema taiwanés o bopomofo.

${ }^{25}$ Existen tres versiones de este hecho. Una placa junto al arco afirma que la comunidad de ultramar china realizó la inversión para su instalación. Otra versión indica que el gobierno de la ciudad de Buenos Aires realizó la donación como muestra de la amistad con el pueblo chino. Finalmente, se especula que el gobierno chino envió los materiales y pagó la construcción en conmemoración de los 60 años de la República Popular China. 
territorio que ellos habían ocupado: «los chinos vinieron y pusieron un arco y le pusieron China Town, que es más grande que la calle Taiwán».

Si bien las mejoras al barrio fueron paulatinas y aún está pendiente la peatonalización, ${ }^{26}$ desde 2003 en adelante comienza una serie de transformaciones que tuvieron una mayor escalada en 2013 y 2014, cuando los supermercados y restaurantes que se instalaron adoptaron un estilo gourmet, tratando de diferenciarse de aquellos que fueron blanco de denuncias en los medios de comunicación a finales de 2013: «sin los olores de los otros supermercados y en un ambiente lindo y cuidado». ${ }^{27}$

\section{La cuestión China-Taiwán EN ALGUNAS TRAYECTORIAS TAIWANESAS ${ }^{28}$}

Su-chen ${ }^{29}$ es profesora de inglés, tiene 40 años y dos hijos. Nació en Taiwán, en una familia en la que algunos miembros provenían de China continental y otros eran nativos de la isla. Llegó en la década de los ochenta a la edad de 10 años a Argentina. Se dedicó a enseñar castellano a niños taiwaneses, y luego empezaría a dar clases de chino mandarín a argentinos. Con los años esta actividad la llevó a montar una institución de enseñanza del idioma y de múltiples disciplinas chinas con un público en su amplia mayoría argentino. Sin embargo, no duda en identificarse como «muy china». Su-chen se siente china, dice ser china, a pesar de ser taiwanesa. Imagina a su instituto como un referente de la cultura china en Buenos Aires. Y en esta idea probablemente haya influencias de su padre, quien desde Taiwán se oponía tanto al régimen de Chiang Kai Shek como al de Mao Tsé Tung. El primero,

${ }^{26}$ Actualmente se corta el tránsito los días domingos. La asociación Barrio Chino se propone la peatonalización todos los días de la semana.

27 Victoria Schirinian da cuenta de este auge gourmet en el Barrio Chino en esta nota: http:// malevamag.com/el-novedoso-lado-gourmet-y-chic-del-barrio-chino/

${ }_{28}$ Para profundizar sobre las trayectorias de migrantes taiwaneses véase Denardi (2013).

${ }_{29}$ Si bien la mayoría de los inmigrantes adopta un nombre occidental, hemos decidido reemplazarlos por nombres orientales de los más frecuentes con el fin de preservar su confidencialidad.

$56 \frac{\text { PRIMER SEMESTRE } 2016}{\text { MIGRACIÓN Y DESARROLLO NÚM. } 26}$ 
por imponer un gobierno dictatorial en la isla; el segundo por las múltiples políticas que modificaron, prohibieron y destruyeron el pasado cultural milenario de China. Su padre es partidario de un «Taiwán para los taiwaneses» y entiende que la «cultura china» está separada de la cuestión política.

Jung es hijo de un matrimonio entre un taiwanés y una china de República Popular China, que una vez casada se muda a Taiwán. Él dice ser chino porque «los 5,000 años de historia y cultura china están por encima de los 60 años de conflicto político entre China y Taiwán». Actualmente se desempeña como locutor de las festividades más importantes de la «comunidad china»; es el maestro de ceremonias que la embajada contrata para mantener reuniones con la presidenta de Argentina, para lanzar el primer programa de enseñanza del idioma chino en la televisión argentina ${ }^{30}$ o para participar en el Mundial de Tango con sede en Beijing. Ambos han desarrollado sus emprendimientos laborales desde los cuales imparten un repertorio basado en la «fusión» o de la «integración» cultural de la colectividad china con la taiwanesa y de estas dos con la argentina.

La historia de Fang-fang es muy diferente a la de Su-chen y Jung. Ella llegó a los 8 años desde Taiwán, a mediados de los años ochenta. Estudió medicina y ahora trabaja en prestigiosos hospitales públicos de la ciudad de Buenos Aires. Proviene de una familia de profesionales muy vinculada con la Iglesia presbiteriana. Las razones de venir a Argentina fueron netamente políticas: aparentemente sus padres figuraban en una «lista negra» del Kuomintang por ser parte de esta Iglesia. Familiares que ya estaban radicados en Argentina, les dijeron que aquí podrían educar a los hijos «con mayor libertad».

En esta Iglesia en particular, el «culto» se realiza en dialecto taiwanés. Surge de la influencia de los misioneros que llegaron a Taiwán con la colonización holandesa en 1624, quienes evangelizaron gran cantidad de indígenas, aprendiendo su idioma, su música y contrayendo matrimonio con

${ }^{30}$ El programa desarrollado por Muralla Dorada, fue pensado en un primer momento para enseñar chino a los argentinos. Tras 15 episodios al aire, los productores se enteran de que los chinos lo usan para aprender español. Se puede ver los episodios vía YouTube o desde http://chinobasico.com/ 
las mujeres. Fang-fang se ha socializado, entonces en un entorno muy tradicionalista: practica el presbiterianismo en dialecto taiwanés, en un espacio en donde se reafirma constantemente el anhelo de la «libertad para Taiwán» y la riqueza identitaria taiwanesa, con intención precisa de diferenciarse de los chinos en sentido estricto. Los 60 años de historia y política que afectaron a las relaciones entre China y Taiwán, y que para Jung y Su-chen no marcan diferencia alguna, Fang-fang los resalta como una división ineludible. Son cada vez menos los puntos en común entre el continente y la isla.

En el grupo juvenil de la iglesia, uno de los temas que ella trabaja con los jóvenes y adolescentes, es el de la identidad. Fang-fang se siente una «mezcla»: mitad taiwanesa, mitad argentina: «me siento una mezcla, soy como una especie en extinción, el pastor nos dice que tenemos rasgos pero cuando vamos a Taiwán, nos ha pasado, todos los que hemos ido, hemos estado hablando en taiwanés y nos han dicho ustedes no son de acá, no? Entonces somos extranjeros en los dos lados, somos una mezcla».

Los chinos de República Popular China no aparecen en sus conversaciones, y si lo hacen, aparecen tibiamente bajo el título de «herméticos». Afirma que le molesta que los argentinos con los que tiene contacto digan que «Taiwán y China son lo mismo». Fang-fang reconoce sus antepasados chinos, pero a la vez sostiene que ella es taiwanesa, no china en sentido amplio, debido a que ya surgieron muchas diferencias entre los chinos de República Popular China y taiwaneses. Estas diferencias remiten tanto a las costumbres, dialectos, etc. de los grupos étnicos propios de Taiwán, como a las diferencias que se fueron abriendo paso tras los casi 60 años de tensión política y de instauración de un modelo económico y político diferente al de la República Popular China.

La misma distinción surge en los relatos de Chen, una taiwanesa que llegó a Buenos Aires hace casi 20 años. Su familia proviene de una región agrícola y siempre han vivido en Taiwán. La decisión de viajar a Argentina se dio por contactos con amigos. Desde que llegó, se dedicó a la enseñanza del chino mandarín. Vino sola a Argentina, y así permaneció hasta que hace dos 
años atrás llegó su sobrino ${ }^{31}$ a quedarse y estudiar en el país. A pesar de todo, ella nos aclara: «Si me encuentro frente a una china, voy a decir que soy taiwanesa. Pero si vos me preguntás, mis antepasados vienen de China, así que sí, soy china».

Estamos ante otro caso de sentirse chino en «sentido amplio». Lo que diferencia a Chen de Jung o Su-Chen es que ella desliza algunas categorías morales que ponen distancia entre los chinos en sentido amplio y chinos en sentido estricto y al mismo tiempo los une. Los «chinos continentales que no comprende[n]», nos dice tocándose la sien y moviendo de un lado hacia el otro la cabeza. Chen se refería particularmente a los inmigrantes provenientes de Fujian, quienes en su mayoría trabajan en los locales del Barrio Chino y sobre los cuales, incluso chinos provenientes de otras provincias de la República Popular China, opinan que son «brutos» y que «sólo viven para trabajar». Pero por otro lado, nos sugiere que para comprender la «cultura china», tendría que hablar con inmigrantes taiwaneses, dando cuenta de que los taiwaneses también pertenecen a esta cultura.

Otra joven de más de 35 años, nacida en Argentina de padres taiwaneses, se presenta e identifica como china, minimizando toda diferencia entre chinos y taiwaneses. Sus padres llegaron a Argentina promediando la década de los setenta. Ambos siguen reivindicando la figura de Chiang Kai Shek. Quizás esta ideología política los lleva a identificarse como chinos, anhelando la unión de China y Taiwán como este líder aspiraba.

\section{La cuestión China-Taimán EN LAS CELEBRACiONES DEL AÑo NUEVo}

Estas diferenciaciones entre chinos continentales y taiwaneses que se suceden en el Barrio Chino y en la cotidianidad de los migrantes, también se vuelcan en las celebraciones de Año Nuevo. Hasta 2006 la celebración del

${ }^{31}$ Para profundizar sobre los conflictos entre chinos y taiwaneses en Buenos Aires (ver: Denardi, 2013 y 2015). 
Año Nuevo Chino se realizaba a puertas cerradas, en la Asociación Civil Chinos de Taiwán. Ese año, la Asociación Barrio Chino y algunos jóvenes colaboradores, también taiwaneses, decidieron hacer un evento en la calle. Desde ese 2006 hasta la actualidad, el festejo ha crecido de manera tal que actualmente Buenos Aires es una de las ciudades de América Latina que más convocatoria reúne, contando en la última edición de 2014 con más de 120,000 asistentes. ${ }^{32}$ Los organizadores contaron con apoyo de la Embajada de China y de los comerciantes taiwaneses del Barrio Chino, pero las condiciones siempre fueron las siguientes: no habría banderas ni de Taiwán ni de China, y por lo tanto no se daría un espacio especial a ninguna autoridad de las comunidades.

En 2014, la Fundación Muralla Dorada se hizo cargo del evento, como única auspiciante y organizadora. Del grupo de los tres jóvenes taiwaneses, sólo uno quedó como organizador. Los dos restantes decidieron dejar de participar, ya que no aceptarían los modos de manejarse de Muralla Dorada. En esta última edición, la bandera de la República Popular China estuvo presente en el escenario durante los dos días que duró el festejo. El embajador de China en Argentina fue el encargado de realizar «el clavado de pupilas» del dragón que dio inicio al evento. El parque cercano al Barrio Chino donde se ubica el escenario se llenó de banderas chinas y argentinas intercaladas. Las banderas y el embajador en un rol predominante rompieron las bases del acuerdo tácito que permitía que chinos y taiwaneses celebraran juntos «la cultura china» más allá de sus diferencias políticas.

\section{A MODO DE CONCLUSIÓN}

Las dinámicas de las relaciones de las organizaciones de inmigrantes chinos en Argentina se encuentran en pleno desarrollo. Es clara la sensación de estar

32 El impacto de estos eventos en los medios argentinos ha sido creciente. Móviles de todos los medios acuden al festejo. Los miembros de la comunidad son reticentes a participar en otros eventos - como el patio de las colectividades en Av. de Mayo- porque no les es redituable económicamente. Si el evento es cercano al barrio chino y multitudinario como el año nuevo y la fiesta de la luna, sí participan con stands.

$60 \frac{\text { PRIMER SEMESTRE } 2016}{\text { MIGRACIÓN Y DESARROLLO NÚM. } 26}$ 
registrando un proceso incipiente, con lazos ya consolidados, otros emergentes y probablemente muchos otros por venir. Hay vínculos familiares y translocales con la zona específica de origen, además de relaciones económicas, religiosas y culturales en un sentido amplio. En el caso de China continental es claro el fuerte rol del Estado. La mayoría de los contactos formales de las organizaciones de inmigrantes son con autoridades locales o regionales chinas, o con líderes de asociaciones relacionadas con «ultramar». Resulta imposible desde Argentina saber más acerca de estas asociaciones de ultramar, su carácter estatal o civil y su historia.

Comparativamente, son relaciones transnacionales modestas, con donaciones económicas, pero sin un peso que sea relevante para el lugar de origen. El transnacionalismo que observamos en la comunidad china y taiwanesa en Argentina es incipiente si lo comparamos con el desarrollado en países como Australia, Canadá (Guerra Zamponi, 2010) y Estados Unidos (Zhou y Lee, 2014). Por un lado, las largas distancias y por ende los elevados costos hacen más esporádicos los viajes entre China y Argentina. Además, la migración asiática en los países mencionados anteriormente comenzó hace más tiempo y en mayor número (menos de 150,000 en Argentina, casi 4 millones en Estados Unidos y alrededor de 1 millón en Canadá y Australia), por lo que la cantidad de organizaciones es mucho mayor: frente a las 80 que pudimos relevar en Argentina. Solamente en tres ciudades de Estados Unidos, Zhou y Lee contaron casi 1,400.

Pero fundamentalmente, es el tipo de organizaciones lo que nos da la pauta de un transnacionalismo incipiente en Argentina. Zhou y Lee (2014: 54 indican que las organizaciones modernas de migrantes chinos en Estados Unidos tienen las siguientes características: la familia, el clan o la ciudad de origen ya no son la base de la organización; la estructura organizacional es horizontal; los objetivos se orientan a incorporar a los miembros de la sociedad de recepción y ya no tanto a desarrollar el lugar de origen. En Argentina, en cambio, una parte relevante de las organizaciones adoptan los nombres y nuclean los miembros de sus ciudades de origen, fundamentalmente con el objetivo de realizar conexiones con funcionarios y empresarios de esos mismos lugares y conservan una estructura organizacional jerárquica. Sin embargo, de los datos recabados por nuestra investigación, entendemos que 
las organizaciones en Argentina seguirían el camino de las de los otros países mencionados al insertarse en el plan económico expansionista del gobierno de la República Popular China. No encontramos en absoluto relatos o situaciones de barrios o poblados en China que dependan siquiera parcialmente de las remesas de los inmigrantes en Argentina.

Las frases de nuestros entrevistados sobre las donaciones, como «mandamos ayuda por los terremotos» tienen relación también con «mandamos ayuda por la inundación de La Plata». Son acciones que otorgan legitimidad y prestigio a las asociaciones; parecen tener más peso para quienes viven en Argentina que en la zona de origen. Tres profesionales argentinos que asesoran a organizaciones chinas nos informaron en distintas entrevistas que ellos aconsejaron a los líderes que, una vía ideal para vincularse y ser reconocidos, es realizar donaciones. En las asociaciones pueden verse, en idioma chino, el nombre y el monto de las donaciones realizadas en cada ocasión. La mayor parte de los contratos son a la distancia, con escasas excepciones, relacionadas por viajes económicos o religiosos, o algún viaje personal. Hay otro nivel de vinculación que pasa principalmente por la relación entre el Consejo Chino para el Fomento del Comercio Internacional (CCPIT).

Por otra parte, cabe señalar que en el caso de los chinos continentales no resulta muy claro hasta dónde existen espacios cívicos y hasta dónde llega la acción del Estado. De hecho, nos preguntamos si alguna de las organizaciones que entrevistamos no ha sido iniciativa del Estado apuntando a una política de unificación nacional de los chinos de "ultramar» (Barabantseva, 2012). En contraste, entre los taiwaneses los roles entre quienes son funcionarios del Estado y quienes son líderes civiles están claramente diferenciadas. A esto se agrega que hay una «lealtad nacional» cultivada, que entre algunas asociaciones es más relevante que en otras. Es posible que en el caso de Taiwán aparezcan como más «aceitadas» las relaciones, quizás también por ser una inmigración más antigua.

Evidentemente, en las relaciones argentino-chinas, en pleno crecimiento, el papel de la Embajada está centrado en grandes acuerdos vinculados con el comercio (soja y manufacturas chinas), inversiones (ferrocarriles, represas, petróleo, finanzas) y cuestiones políticas (BRICS, Malvinas, Taiwán, etc.). En estos planos, los inmigrantes chinos en Argentina no parecen cumplir

$62 \frac{\text { PRIMER SEMESTRE } 2016}{\text { MIGRACIÓN Y DESARROLLO NÚM. } 26}$ 
papel alguno. En cambio, sí es factible constatar que algunas organizaciones son facilitadoras de visitas de potenciales inversores, recibiendo y acompañando a los visitantes.

Si nos preguntamos acerca de cuál es el peso del Estado chino sobre estas organizaciones puede constatarse que mantienen excelentes relaciones con varias de ellas. Incluso, la embajada deriva en algunas organizaciones demandas de actividades culturales, como la organización del Año Nuevo Chino, la enseñanza del idioma chino mandarín, un programa de televisión y actividades de cultura argentina en China. Las características precisas de las relaciones entre el Estado y todas las organizaciones no pueden establecerse con plena claridad. A nuestro entender, esa falta de claridad es un dato en sí mismo, ya que en otros grupos migrantes la separación entre el Estado y las organizaciones es tajante y evidente.

Una comparación para finalizar; un estudio de principios de los años noventa ha relevado las características de la diáspora china en dos ciudades diferentes de Estados Unidos. Waldinger y Tseng (1992) analizan de manera comparada los chinos de Nueva York y de Los Ángeles. Mientras los primeros permanecieron en el barrio chino y desarrollaron su vida de manera intracomunitaria, los chinos de Los Ángeles se establecieron en diferentes barrios de la ciudad y desarrollaron lo que los autores califican como una exitosa integración a la sociedad norteamericana. Waldinger y Tseng mencionan, aunque no destacan, que los que ellos denominan «chinos de Los Ángeles» son en realidad migrantes provenientes de Taiwán. Más allá de la denominación, las procedencias de los migrantes nos indican procesos migratorios diferentes, dada la discrepancia entre el volumen de recursos económicos y culturales que existe entre los dos grupos.

En Argentina, como mencionamos, la primera ola de migrantes de un número considerable fue la de taiwaneses. Las disputas y diferencias entre chinos y taiwaneses surgen de la necesidad de estos últimos de diferenciarse de los primeros, que provenían de zonas rurales, poco alfabetizadas y muy pobres. Sin embargo, ante los cambios del papel de China en la economía mundial y la relación estratégica integral que está construyendo con Argentina, estamos evidenciando que muchos taiwaneses, aluden a sus antepasados para dar cuenta de una pertenencia al legado cultural e histórico chino. Es por 
esto que en Buenos Aires encontramos migrantes taiwaneses que se consideran chinos (en sentido amplio) por pertenecer a una cultura que va más allá de los 60 años de conflicto geopolítico entre los dos países. Diferentes procedencias, distintas zonas de asentamientos y contextos nacionales diversos configuran situaciones donde las organizaciones, las identificaciones y el transnacionalismo adquieren dinámicas contrastantes.

\section{Bibliografía}

Barabantseva, Elena (2012), "Who are "Overseas Chinese Ethnic Minorities"? China's Search for Transnational Ethnic Unity», Modern China, Los Ángeles, California, 38, núm. 1.

Bialogorski, Mirta y Daniel Bargman (1996), «Articulación interétnica en medio urbano: judíos y coreanos en Buenos Aires», Estudios Migratorios Latinoamericanos, núm. 32, Buenos Aires.

BOGADO BordAZAR, Laura (2002), «Migraciones internacionales. Influencia de la migración china en el Río de la Plata», tesis de maestría en Relaciones Internacionales, La Plata, UnLP.

Brage, Eugenia (2010), «Redes sociales y asociaciones civiles taiwanesas en la ciudad de Buenos Aires», manuscrito.

Bretal, Eleonor (2006), “iAy, este chino habla castellano!”. El caso de los jóvenes inmigrantes de origen taiwanés en la ciudad de La Plata», Jornada de Sociología, núm. 4.

CASALS, Pamela (2009), «Inserción de los supermercadistas chinos en la ciudad de Mar del Plata», manuscrito, Mar del Plata, Universidad Caece.

Castiglione, Celeste (2013), "Interacciones y desplazamientos: Relaciones interétnicas entre la colectividad coreana y los chosunjok (chinos de origen coreano)", manuscrito.

DenARDI, Luciana (2013), "Categorías morales y trayectorias de inmigrantes taiwaneses en la Ciudad de Buenos Aires. Ser chino —en sentido amplio-y ser taiwanés", Jornadas Interdisciplinarias de Jóvenes Investigadores en Ciencias Sociales, Buenos Aires, UnSAM.

(2015), «Ser chino en Buenos Aires: Historia, moralidades y cambios en la diáspora china en Argentina», Revista Horizontes Antropológicos, núm. 43, Porto Alegre.

$64 \frac{\text { PRIMER SEMESTRE } 2016}{\text { MIGRACIÓN Y DESARROLLO NÚM. } 26}$ 
EDel, May y Abraham Edel (1959), Anthropology and Ethics, Springfield, Illinois, Charles C.Thomas.

Guerra Zamponi, Carolina (2010), «La Diáspora china», materiales de conferencias, seminarios y reuniones de trabajo, Consejo Argentino para las Relaciones Internacionales, Buenos Aires, núm. 6, en http://www.cari.org.ar/pdf/mcsrt6.pdf (09/12/2015).

LABORDE, Soledad (2011), "La alteridad inmigrante en la ciudad del siglo XXI: Nuevas formas de construcción del espacio público», Revista de Ciencias Sociales CS, núm. 7, Cali, Colombia.

PaCCECA, María Inés y Carolina Courtis (2008), «Inmigración contemporánea en Argentina: dinámicas y políticas». Serie Población y Desarrollo, núm. 84, Chile, Cepal-Celade.

PAPPIER, Andrea (2011), «Inmigración china en Argentina. El Barrio Chino de Buenos Aires como caso de estudio intercultural», Congreso de la Aladaa, núm. 13, Buenos Aires.

SASSONE, Susana y Carolina Mera (2006), «Barrios de migrantes en Buenos Aires: Identidad, cultura y cohesión socioterritorial», manuscrito.

Trejos, Bernardo y Nora Chaing (2012), "Young Taiwanese Immigration to Argentina: the Challenges of Adaptation, Self-Identity and Returning», International Journal of Asia Pacific Studies: IJAPS, 8, núm. 2, Malasia.

WaLDINGER, Roger y Yenfen Tseng (1992), «Divergent Diasporas: the Chinese Communities of New York and Los Angeles Compared», Revue Europeene de Migrations Internationaux, 8, núm. 3, Francia.

ZHANG, Tuo (2007), «Inmigrantes chinos en Argentina, una comunidad joven, dinámica y amante de una convivencia armoniosa», Revista de la Copppal, 7, verano.

ZHou, Min y Rennie Lee (2015), "Traversing Ancestral and New Homelands: Chinese Inmigrant Transnational Organizations in the United States», en A. Portes y P. Fernández Kelly (eds.), The State and the Grassroots: Immigrant Transnational Organizations in Four Continents, Oxford, UK, Berghahn Books.

ZuZeK, Cristina (2004), «Identidad y aculturación: el caso de los inmigrantes taiwaneses jóvenes», tesis de licenciatura en Sociología, Buenos Aires, Instituto de Investigación en Ciencias Sociales (IDICSO), Facultad de Ciencias Sociales, Universidad del Salvador. 


\section{AnExo}

\section{GRÁFICA 1}

Porcentaje de organizaciones relevadas por tipo de organización

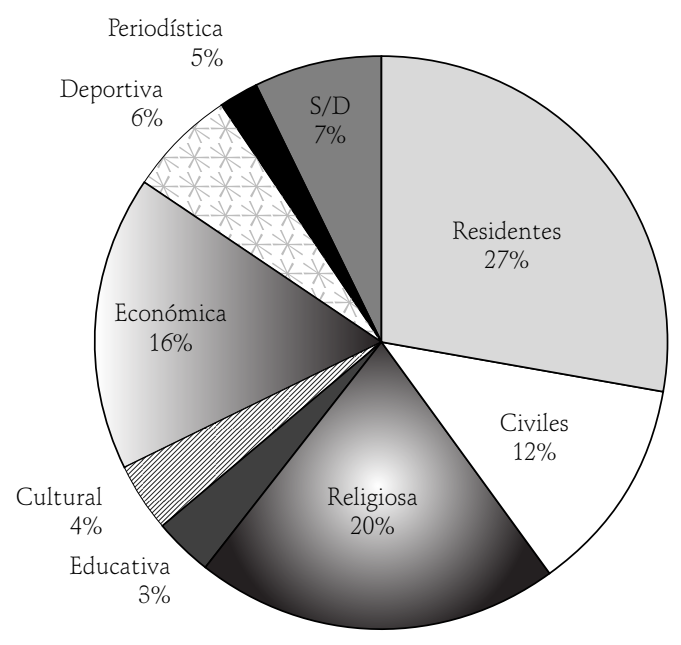

\section{GRÁFICA 2}

Porcentaje de organizaciones relevadas por grupo migratorio

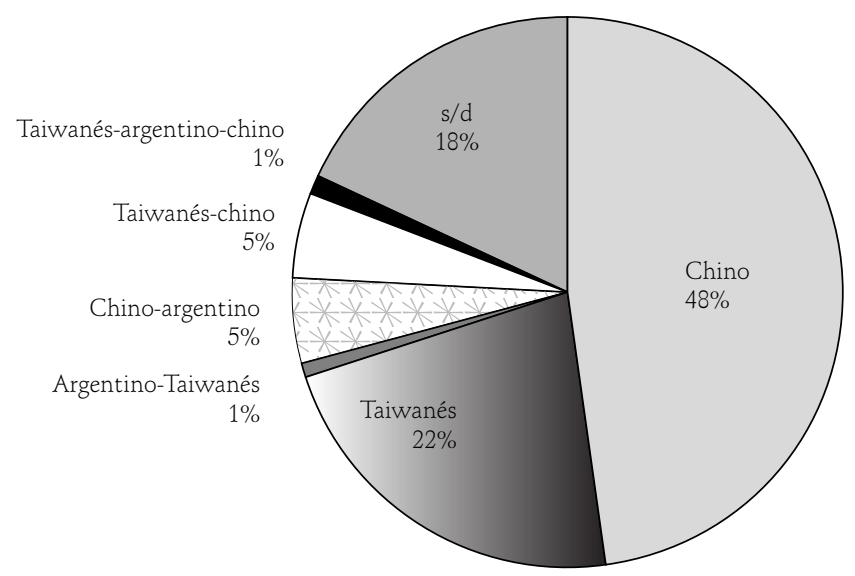

$66 \frac{\text { PRIMER SEMESTRE } 2016}{\text { MIGRACIÓN Y DESARROLLO NÚM. } 26}$ 


\section{GRÁFICA 3}

Porcentaje de organizaciones encuestadas por tipo de organización

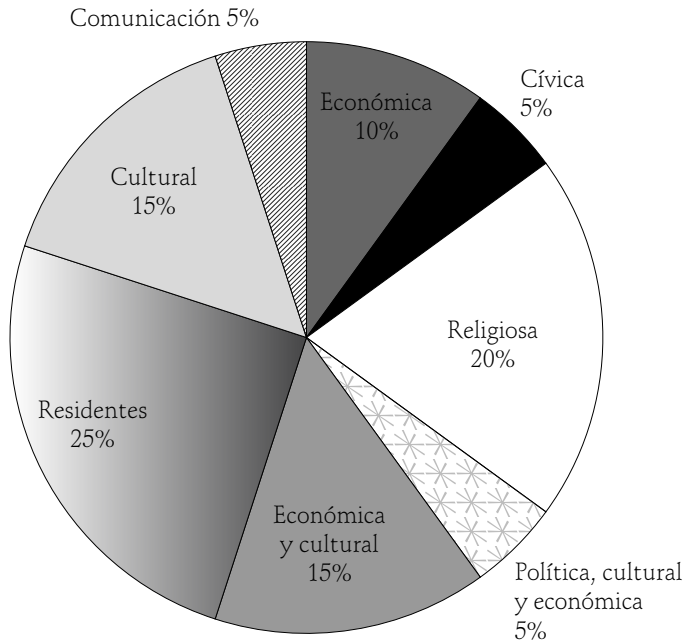

\section{GRÁFICA 4}

Porcentaje de organizaciones encuestadas por motivos que promovieron la creación de la organización

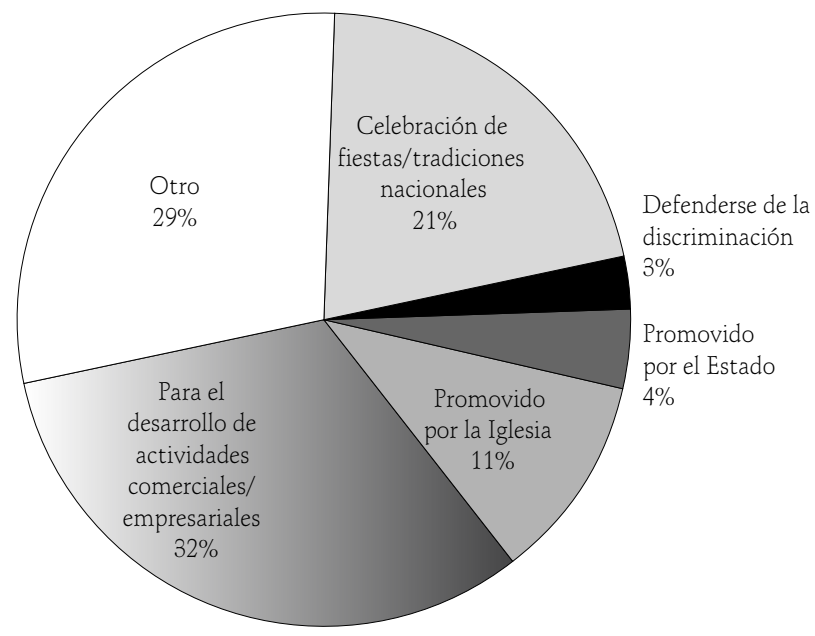




\section{GRÁFICA 5}

Porcentaje de organizaciones encuestadas por país donde está centrado su objetivo

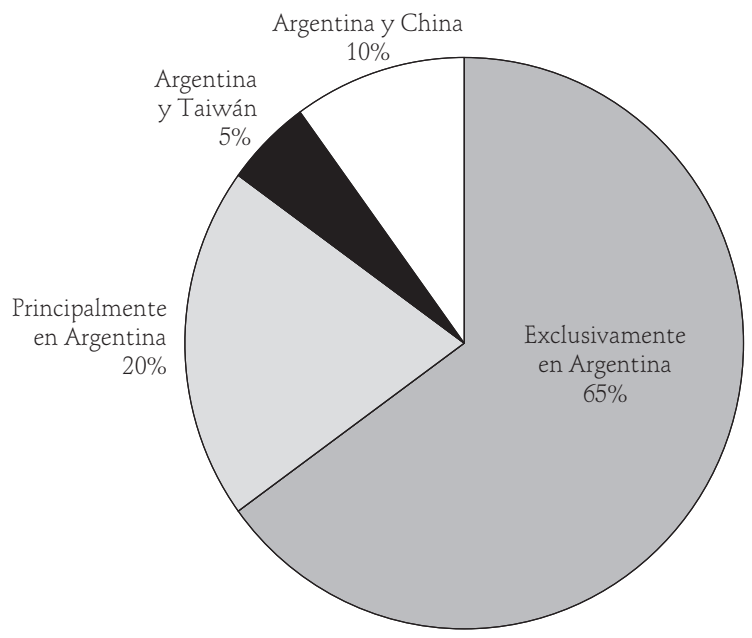

GRÁFICA 6

Porcentaje de organizaciones encuestadas por nivel en el que se centra su objetivo

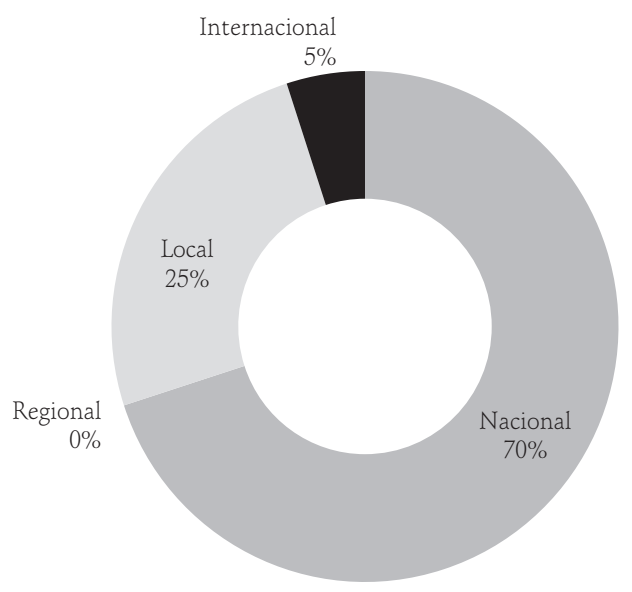

$68 \frac{\text { PRIMER SEMESTRE } 2016}{\text { MIGRACIÓN Y DESARROLLO NÚM. } 26}$ 


\section{GRÁFICA 7}

Número de organizaciones por principales actividades que desarrollan

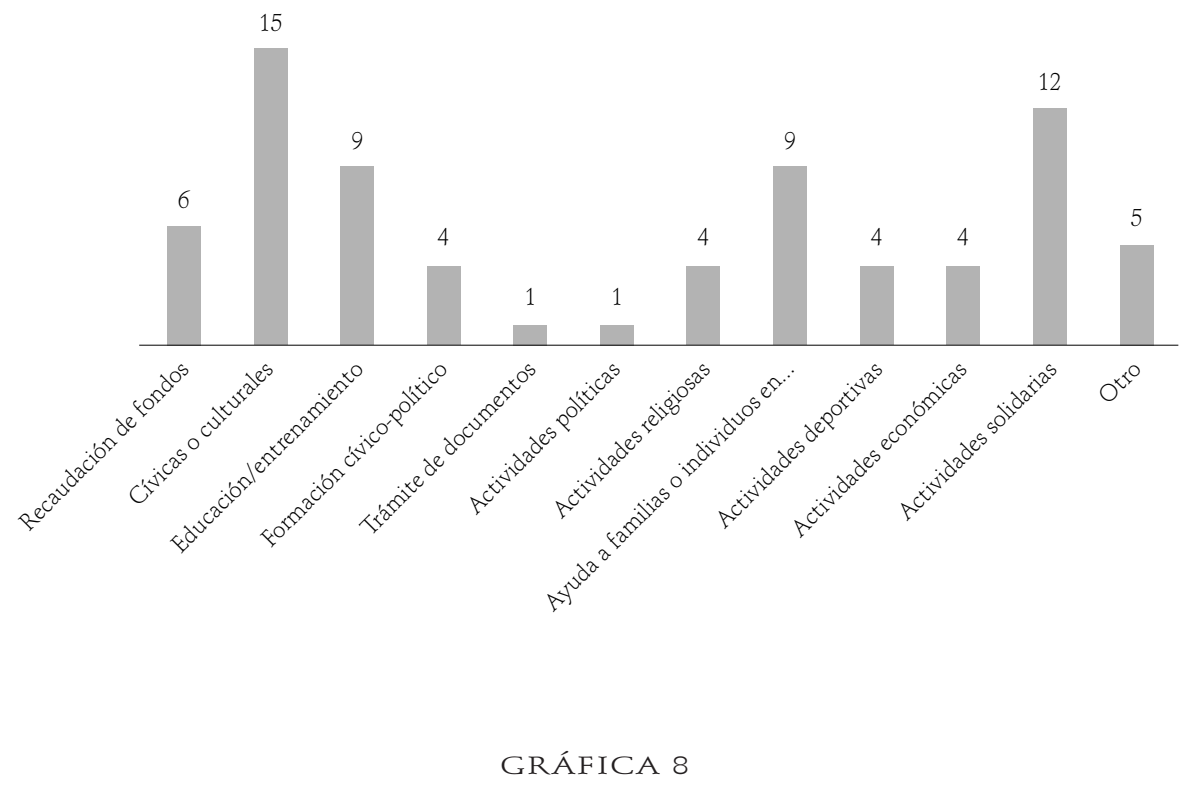

Número de organizaciones por tiempo en el cargo de su actual líder

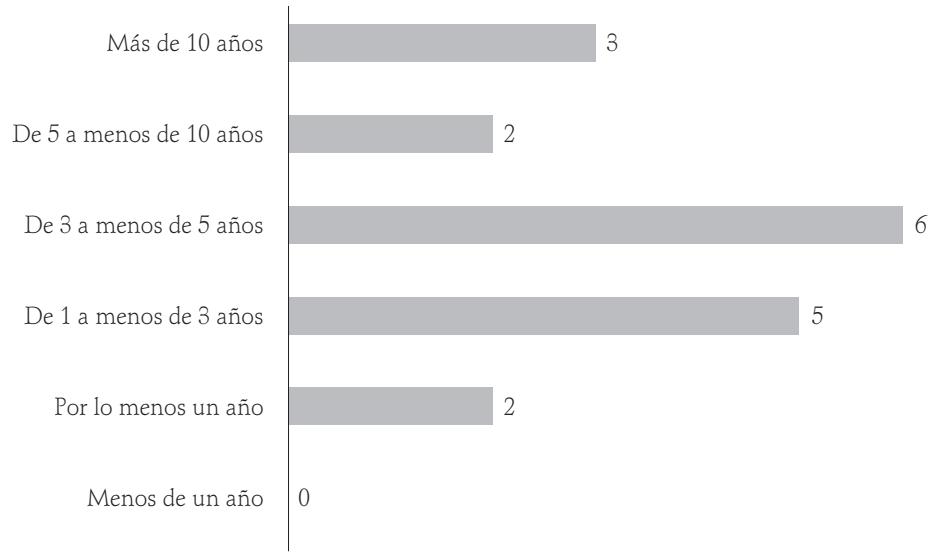




\section{GRÁFICA 9}

Número de organizaciones por cantidad de miembros activos

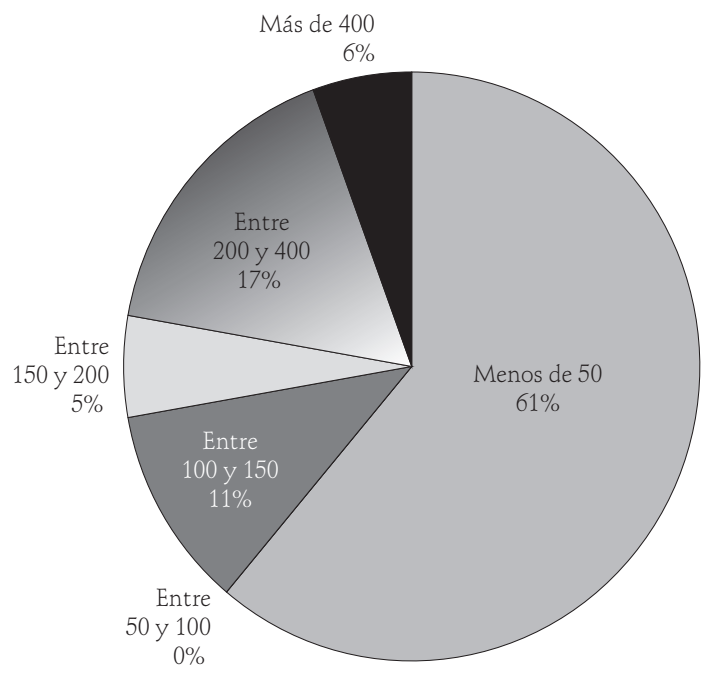

GRÁFICA 10

Porcentaje de organizaciones con relaciones regulares con representantes del poder ejecutivo chino

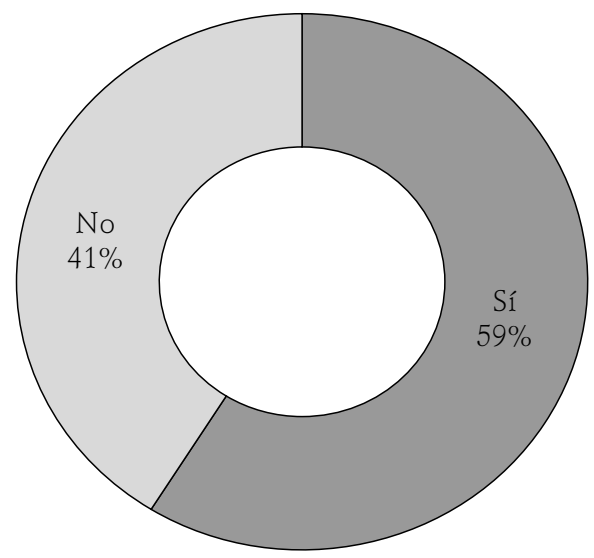

$70 \frac{\text { PRIMER SEMESTRE } 2016}{\text { MIGRACIÓN Y DESARROLLO NÚM. } 26}$ 


\section{GRÁFICA 11}

Porcentaje de organizaciones con relaciones regulares con representantes del poder legislativo chino

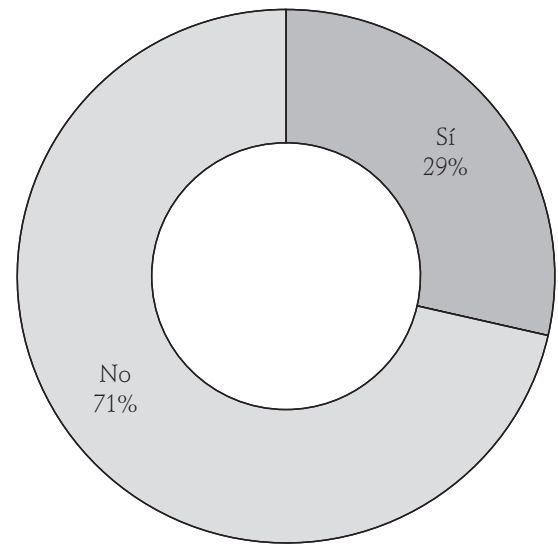

GRÁFICA 12

Porcentaje de organizaciones en relación con la influencia de la participación en la organización sobre el mantenimiento de vínculos de sus miembros con el país de origen

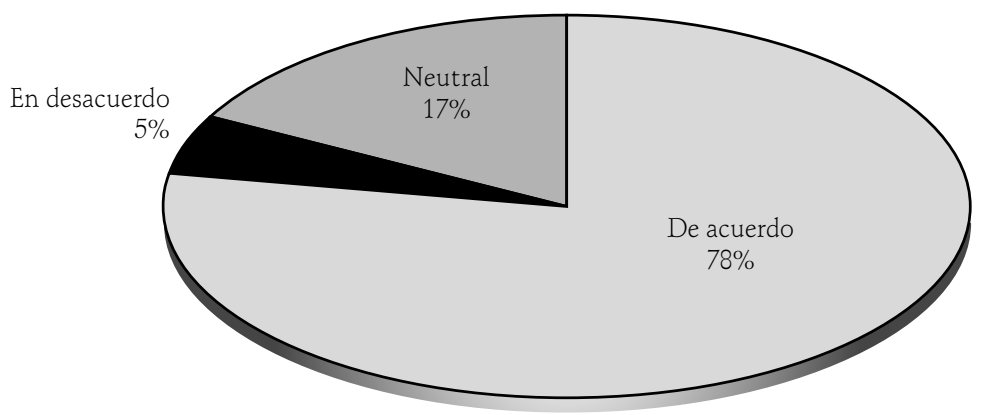




\section{GRÁFICA 13}

Porcentaje de organizaciones en relación con la influencia de la participación en la organización sobre el mantenimiento de vínculos con el país de origen de la comunidad

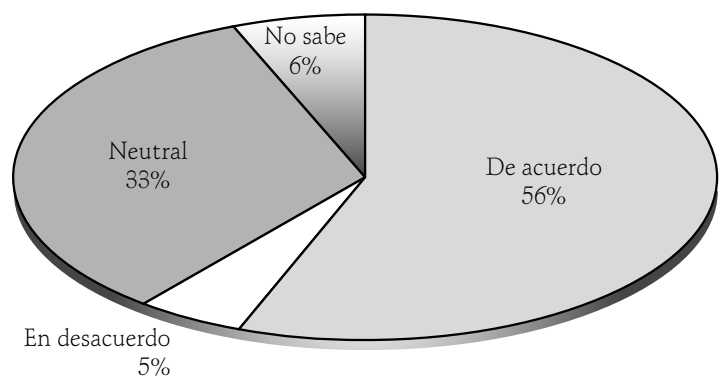

GRÁFICA 14

Cantidad de organizaciones en relación con la frecuencia de su comunicación con China/Taiwán

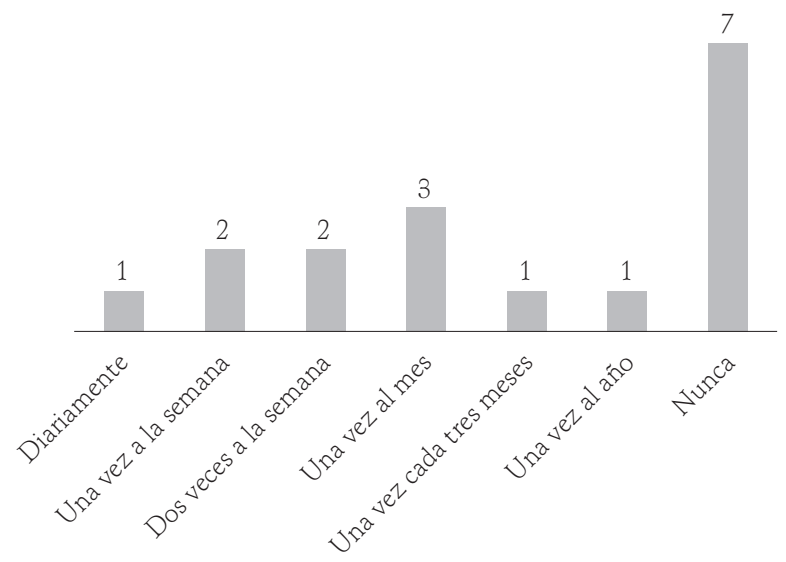

$72 \frac{\text { PRIMER SEMESTRE } 2016}{\text { MIGRACIÓN Y DESARROLLO NÚM. } 26}$ 


\section{GRÁFICA 15}

Cantidad de organizaciones en relación con la frecuencia de recepción de comunicación desde China/Taiwán

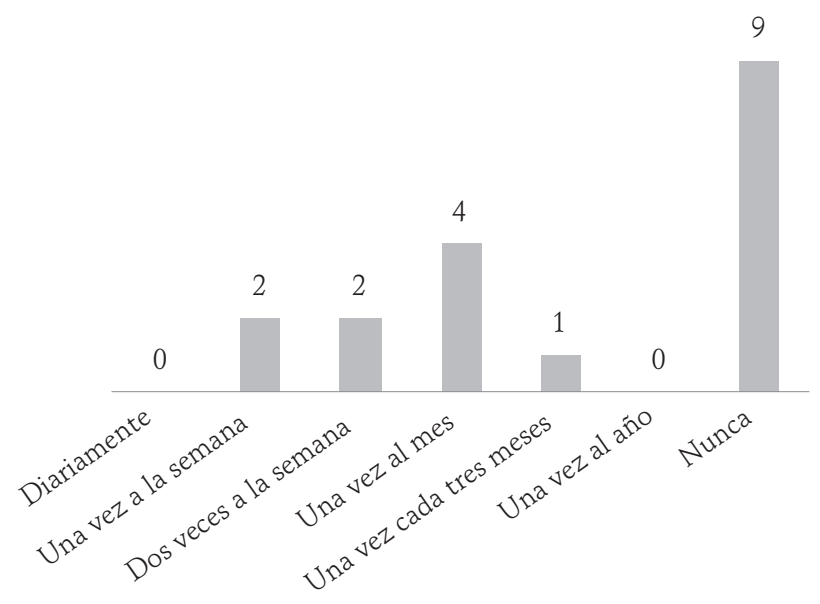

GRÁFICA 16

Cantidad de organizaciones en relación con la frecuencia de viajes hacia China/Taiwán

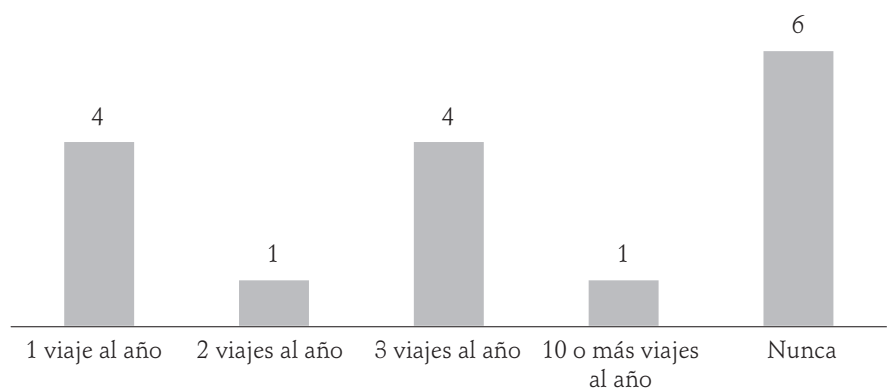


